\author{
Aus dem Fachbereich Medizin \\ der Johann Wolfgang Goethe-Universität \\ Frankfurt am Main \\ betreut am \\ Zentrum der Neurologie und Neurochirurgie \\ Klinik für Neurologie \\ Direktor/in: Prof. Dr. med. Helmuth Steinmetz
}

\title{
Stabilisierung der Blut-Hirn-Schranke nach Thrombolyse unter antithrombotischer Therapie durch LOX Inhibition
}

\author{
Dissertation \\ zur Erlangung des Doktorgrades der Medizin \\ des Fachbereichs Medizin \\ der Johann Wolfgang Goethe-Universität \\ Frankfurt am Main
}

vorgelegt von

Franziska Lieschke

aus Trier

Frankfurt am Main, 2020 



\author{
Aus dem Fachbereich Medizin \\ der Johann Wolfgang Goethe-Universität \\ Frankfurt am Main \\ betreut am \\ Zentrum der Neurologie und Neurochirurgie \\ Klinik für Neurologie \\ Direktor/in: Prof. Dr. med. Helmuth Steinmetz
}

\title{
Stabilisierung der Blut-Hirn-Schranke nach Thrombolyse unter antithrombotischer Therapie durch LOX Inhibition
}

\author{
Dissertation \\ zur Erlangung des Doktorgrades der Medizin \\ des Fachbereichs Medizin \\ der Johann Wolfgang Goethe-Universität \\ Frankfurt am Main \\ vorgelegt von \\ Franziska Lieschke \\ aus Trier
}

Frankfurt am Main, 2020 
Dekan:

Referent:

1. Korreferent:

2. Korreferent:

Tag der mündlichen Prüfung:
Prof. Dr. Stefan Zeuzem

Prof. Dr. Christian Förch

Prof. Dr. Karlheinz Plate

Prof. Dr. Heinfried Radeke

11.05.2021 


\section{Inhaltsverzeichnis}

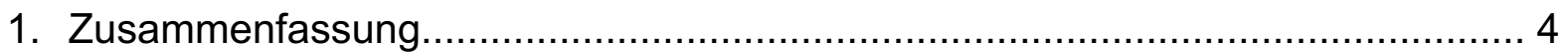

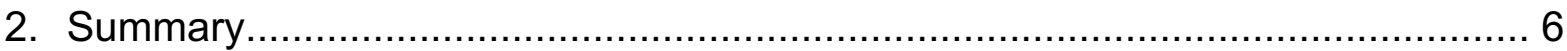

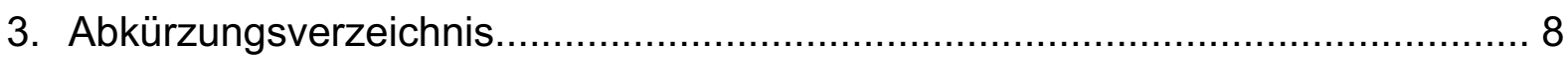

4. Comprehensive summary

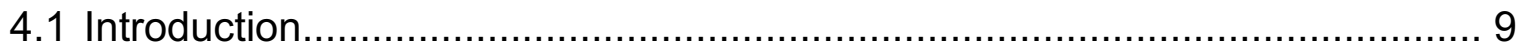

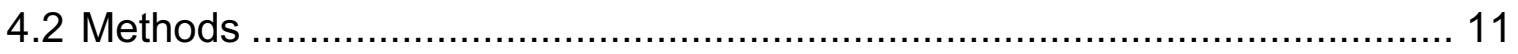

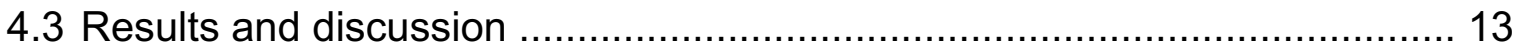

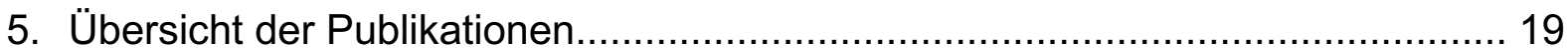

6. Darstellung des eigenen Anteils an den einzelnen Publikationen...................... 20

7. Manuskript "Measurement of platelet function in an experimental stroke model

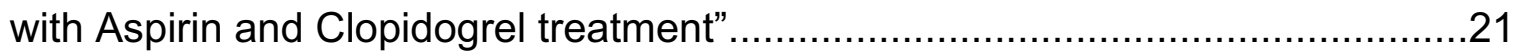

8. Manuskript "Dual Antiplatelet Therapy Increases Hemorrhagic Transformation Following Thrombolytic Treatment in Experimental Stroke"............................. 35

9. Manuskript "Thrombolysis in acute stroke under dual antiplatelet therapy: Perspectives arising from translational studies" .......................................... 49

10. Literaturverzeichnis zu den Zitaten des „Comprehensive summary“ ..................52

11. Anhang

11.1 Does ML351 affect tPA/plasmin activity?

.55

11.2 Visual Abstract of "Dual antiplatelet therapy increases hemorrhagic transformation following thrombolytic treatment in experimental stroke" $\ldots \ldots \ldots . . .57$ 11.3 Supplemental methods of "12/15-LOX-inhibition in ASA+CPG model".......58

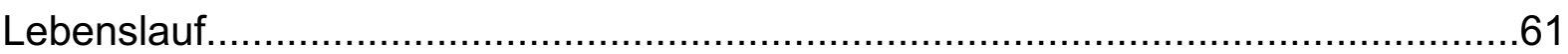

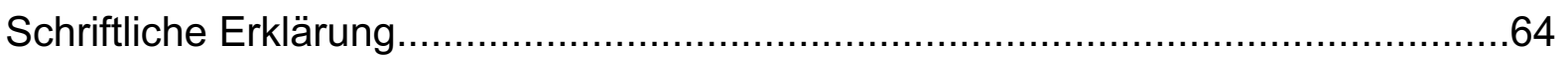

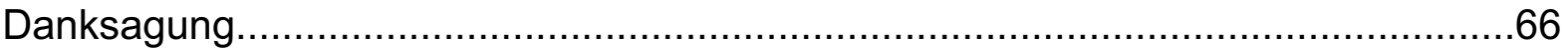




\section{Zusammenfassung}

Duale Thrombozytenaggregationshemmung (,dual antiplatelet therapy: DAPT) erhöht das Risiko für eine hämorrhagische Transformation $(\mathrm{HT})$ von ischämischen Schlaganfällen nach Thrombolyse mit gewebespezifischem Plasminogenaktivator (,tissue plasminogen activator': tPA). Bisherige klinische Studien waren jedoch nicht vollends eindeutig, ob diese erhöhte Blutungswahrscheinlichkeit tatsächlich zu einer schlechteren Ausgangssituation für Patienten führt. Viele sehen die initiale klinische Verschlechterung im Rahmen einer potenziellen HT durch den Nutzen der wiederhergestellten Rekanalisation verschlossener Gefäße aufgewogen. Aus diesem Grunde sollte tPA auch in Patienten angewendet werden, die einen Schlaganfall unter DAPT erleiden. Bisher sind der Pathomechanismus und die beteiligten Mediatoren der HT unverstanden. Allerdings könnte die Reduktion der tPA-assoziierten HT zu einer sichereren Anwendung der Thrombolyse beitragen und ihren Nutzen insgesamt weiter steigern. Daher war es Ziel dieser Studie, ein Schlaganfallmodell mit tPA-assoziierter HT in Mäusen unter DAPT zu etablieren, um damit erste Bewertungen therapeutischer Ansätze zur Begrenzung der HT zu ermöglichen.

Ein entscheidender Aspekt vorab war die Bestimmung der Thrombozytenfunktion in den behandelten Mäusen, um damit die Wirksamkeit der DAPT zu messen. Dies war besonders vor dem Hintergrund wichtig, dass DAPT bei Patienten unterschiedlich wirksam ist. So gibt es einen gewissen Anteil Patienten, der resistent gegenüber Aspirin und/oder anderen Thrombozytenaggregationshemmern wie Clopidogrel zu sein scheint. Daher galt es, dieses Phänomen in unserem Modell zu kontrollieren und etwaige NonResponder zu identifizieren und gegebenenfalls auszuschließen. Dies ist bei herkömmlichen Methoden der Aggregometrie (dem Standardverfahren zur Messung der Thrombozytenfunktion und Therapieüberwachung von Thrombozytenaggregationshemmern) eine Herausforderung, da im Handel erhältliche Aggregometer Blutvolumina erfordern, die für eine Maus tödlich wären. Auch Schwanzblutungstests (sog. „tail bleeding tests“) versagen häufig, wenn sie nach einer experimentellen Schlaganfalloperation durchgeführt werden. Wir haben daher einen Durchflusszytometrie-basierten Ansatz zur Messung der in vitro Thrombozytenfunktion 
modifiziert, der nur geringe Blutvolumina erfordert und von uns erstmals in einem experimentellen Schlaganfallprotokoll eingesetzt wurde. Dieser zeigte eine signifikant reduzierte Thrombozytenfunktion nach DAPT mit Aspirin und Clopidogrel (ASA+CPG) an. Die Methode korrelierte gut mit Ergebnissen von zusätzlich durchgeführten Schwanzblutungstests und wird künftige präklinische Studien zur DAPT in Mäusen erleichtern. Obwohl es eine gewisse Variabilität in der Thrombozytenfunktion der behandelten Mäuse gab, identifizierten wir letztendlich keine Non-Responder.

Als nächstes zeigten wir erfolgreich, dass DAPT mit ASA+CPG in Mäusen beim experimentellen Schlaganfall zu vermehrter HT beiträgt. Wurde die DAPT mit einer HPAThrombolyse verbunden, erhöhte sich die HT-Rate sogar signifikant im Vergleich zu unbehandelten Mäusen mit und ohne tPA-Thrombolyse. Unser Modell kann nun genutzt werden, um die Mechanismen der HT weiter zu untersuchen. Noch wichtiger ist, dass die Einrichtung eines solchen Modells es Forschern ermöglicht, mögliche Strategien zur Minderung des Blutungsrisikos bei Patienten mit DAPT zu testen.

Zur Verringerung der HT wählten wir zwei verschiedene pharmakologische Strategien. Zunächst untersuchten wir die Reduktion der tPA Dosis, welche allerdings nicht erfolgreich vor hämorrhagischen Komplikationen schützen konnte. Danach fokussierten wir uns auf die Rolle der 12/15-Lipoxygenase (12/15-LOX) in unserem Modell. Verschiedene Vorarbeiten hatten gezeigt, dass die 12/15-LOX zum Untergang von Endothelzellen im ischämischen Gehirn beiträgt und damit wahrscheinlich eine ursächliche oder zumindest unterstützende Rolle in der Entstehung der HT hat. So wiederholten wir unsere Versuche der tPA-assoziierten HT unter DAPT in LOX-knockout Mäusen und inhibierten die 12/15-LOX pharmakologisch mit ML351. Wir zeigten erfolgreich, dass die Hemmung von 12/15-LOX in Wildtyp-Mäusen die Blutungsrate signifikant reduzierte und identifizierten die 12/15-LOX damit als geeigneten Kandidaten für weiterführende Studien zur Eindämmung sekundärer Schäden nach ischämischen Schlaganfall. Zudem wäre neben der therapeutischen, auch die prophylaktische Gabe von 12/15-LOX Inhibitoren in Hochrisikopatienten additiv zur Thrombolyse denkbar. Eine solche Blutungsprophylaxe könnte zu einer Indikationserweiterung der Lysetherapie beitragen und das funktionelle Langzeit-Ergebnis der Patienten verbessern. 


\section{Summary}

Dual antiplatelet therapy (DAPT) increases the risk of hemorrhagic transformation (HT) following ischemic stroke after thrombolysis with tissue plasminogen activator (tPA). However, previous clinical studies were not entirely clear whether this increased bleeding risk is indeed detrimental to patient outcome, and many see the possibility of an initial deterioration outweighed by the benefits of recanalization of the blocked vessel. For this reason, tPA should not be withhold from patients on pre-stroke DAPT. So far, the pathomechanism and the mediators involved in tPA-associated HT have not been fully understood. But HT reduction could significantly contribute to the safer use of tPA thrombolysis and further increase its overall benefit. It was therefore the aim of this study to establish a stroke model with IPA-associated HT in mice under DAPT, in order to enable first evaluations of therapeutic approaches to limit HT.

A crucial aspect in advance was to determine the platelet function in the treated mice in order to measure and monitor the DAPT efficacy. This was particularly important given the fact that DAPT efficacy alters in patients, implicating a certain proportion of patients who appear to be resistant to aspirin and/or other antiplatelets such as clopidogrel. It was therefore necessary to control for this phenomenon in our model and to identify and if necessary, to exclude any occurring non-responders. This is challenging with conventional methods like aggregometry (the gold standard for measuring platelet function and monitoring antiplatelet therapy), because commercially available aggregometers require blood volumes that would be lethal to a mouse. Likewise, tail bleeding tests often fail when performed after an experimental stroke operation. We have therefore modified a flow cytometry-based approach to measure in vitro platelet function, which requires only small blood volumes and can be repetitively included into experimental stroke protocols. The method correlated well with results from additional tail bleeding tests and will facilitate future preclinical studies on DAPT in mice. Although there was some variability seen in the platelet function of the treated mice, we did not identify non-responders.

Now that we had proven the DAPT efficacy, we successfully showed that DAPT in mice treated with aspirin and clopidogrel (ASA+CPG) contributed to increased $\mathrm{HT}$ after an 
experimental stroke. If DAPT was combined with tPA thrombolysis, the HT was significantly increased compared to untreated mice with and without IPA thrombolysis. Our model can now be used to further investigate the mechanisms of HT. More importantly, the establishment of such a model enables researchers to test possible strategies to reduce bleeding in patients with DAPT.

As such, we selected two different pharmacological strategies to reduce HT. First, we examined the reduction in the tPA dose, which, however, could not successfully protect against hemorrhagic complications. We then focused on the role of 12/15-lipoxygenase (12/15-LOX) in our model, as various preliminary work has shown that 12/15-LOX contributes to endothelial cell death in the ischemic brain, and therewith probably causes or at least supports the development of HT. We repeated our experiments of tPAassociated HT under DAPT in LOX-knockout mice and pharmacologically inhibited 12/15-LOX with ML351. We successfully demonstrated that inhibition of 12/15-LOX significantly reduced the bleeding rate in wild-type mice and thus identified 12/15-LOX inhibitors as suitable candidates for further studies to encounter secondary damage following ischemic stroke. In addition to the therapeutic administration of 12/15-LOX inhibitors in the acute event of bleeding, a prophylactic administration together with the tPA-thrombolysis in high-risk patients could be possible. Such bleeding prophylaxis might increase the use of TPA, and thus further increase the overall benefit of TPA in patients on antiplatelet therapy, which might finally improve long term functional outcomes. 


\section{Abkürzungsverzeichnis}

$\mathrm{ASA}+\mathrm{CPG}=$ Aspirin and Clopidogrel

$\mathrm{BW}=$ Bodyweight

CD31 = Cluster of Differentiation 31, synonymous Platelet endothelial cell adhesion molecule (PECAM-1)

CD41 = Cluster of Differentiation 41, synonymous Integrin alpha-IIb

$\mathrm{CD} 62 \mathrm{P}=$ Cluster of Differentiation 62-p, synonymous $\mathrm{p}$-selectin

COX $=$ Cyclooxygenase

$\mathrm{d}=$ days

DAPI = 4',6-diamidino-2-phenylindole

DAPT $=$ Dual Antiplatelet Therapy

$\mathrm{DMSO}=$ dimethyl sulfoxide

FACS $=$ fluorescence-activated cell scanning/flow cytometry

$\mathrm{h}=$ hours

$\mathrm{HT}=$ Hemorrhagic Transformation

$\mathrm{KO}=$ Knock-out

LOX $=12 / 15$-Lipoxygenase (mouse), 15-Lipoxygenase1 (human)

$\mathrm{MCA}=$ middle cerebral artery

$\min =$ minutes

(r)tPA = (recombinant) tissue plasminogen activator

sog. = sogenannt

$(\mathrm{t}) \mathrm{MCAO}=$ (transient) middle cerebral artery occlusion

TTC $=$ 2,3,5-triphenyltetrazolium chloride

$\mathrm{WT}=$ wild type 


\section{Comprehensive Summary}

\subsection{Introduction}

Acute stroke is the second leading cause of death and one of the most common causes of disability in Germany and worldwide ${ }^{1}$. Around 1.76 million people in Germany have had a stroke in their lifetime, including 877,000 women and $884,000 \mathrm{men}^{2}$. Up to a third of the patients affected die within the first year after a stroke, while up to $40 \%$ of the surviving patients remain disabled in the long term ${ }^{2}$. Due to demographic change and the aging of the population, an increase in the number of people affected is to be expected in the future, implicating substantial socioeconomic costs ${ }^{3}$.

There are two major types of acute stroke: ischemic stroke, which occurs due to a lack of blood flow in a blocked vessel, and intracerebral hemorrhage which is caused by the rupture of a vessel and is marked by bleeding. Ischemia accounts for approximately $80 \%$ of presentations and can be treated if recognized early ${ }^{4}$. The treatment of ischemic stroke includes the recanalization of the blocked vessel with either a thrombolytic agent such as tissue plasminogen activator (tPA) or mechanical intraarterial thrombectomy using a stent retriever. Commonly a combination of both methods is used in order to rescue tissue under threat of death ${ }^{5,6}$.

Hemorrhagic transformation (HT) of the ischemic stroke due to reperfusion injury remains one significant complication of recanalization therapies and might contribute to unfavorable outcomes and failed regeneration in the long term. Amongst other factors, the previous use of anticoagulants and antiplatelets increases the risk of $\mathrm{HT}$, leading to an increased rate of symptomatic intracerebral hemorrhage $(\mathrm{sICH})$ following IPA thrombolysis ${ }^{7}$. However, it is estimated that up to $45 \%$ of stroke patients are on previous antiplatelet therapy when they experience their stroke ${ }^{8}$. It is still a matter of controversial discussion, whether the benefit of thrombolysis under these conditions outweighs the increased risk of HT. Previous studies indicated a similar survival and functional outcome ${ }^{9-11}$, which is why current guidelines allow for thrombolytic treatment in patients on DAPT. However, the development of symptomatic intracerebral hemorrhages can increase the risk of dangerous deterioration in stroke patients. This might in addition 
contribute to vascular cognitive impairment and dementia ${ }^{12-15}$. These types of long-term brain injury manifest after several years and are not captured in the current clinical outcome studies and thus might be underrated. It appears clear that developing strategies to limit the hemorrhage risk in patients on DAPT receiving IPA is of relevance.

Therefore, the aim of this study was to establish an animal model of DAPT-related HT to further investigate the underlying mechanistic pathways and to provide a platform for testing possible vasculoprotective therapies.

A crucial aspect in advance was to monitor the antiplatelet treatment efficacy in our model. Given the fact that antiplatelet efficacy differs in patients, resulting in a certain number of patients being resistant to antiplatelets ${ }^{16-18}$, it was necessary to be able to identify and if applicable, to exclude non-responders. For this, we employed a flow cytometry-based analysis of platelet activation markers and sought to demonstrate the feasibility to incorporate these tests into an experimental stroke model. In addition to monitoring the antiplatelet therapy, we aimed to investigate the influence of platelet function on HT development in more detail.

Pursuing our main objective of combating $\mathrm{HT}$, we aimed to initially evaluate strategies counteracting the hemorrhagic outcome. In order to increase tPA safety especially in high risk patients, the use of low-dose tPA was intensively studied in the past ${ }^{19-22}$. As such, the investigators of the ENCHANTED trial identified a borderline significant interaction $(p=0.052)$ for a better functional outcome when using low-dose tPA ${ }^{23}$ in patients on pre-stroke antiplatelet therapy. Adapting this approach to our mouse model, we scaled down the tPA dose by the same percentage as in human patients and aimed to evaluate its efficacy in decreasing the rate of $\mathrm{HT}$.

Finally, we aimed to evaluate the use of 12/15-lipoxygenase (12/15-LOX) inhibition as an acute prophylactic vasculoprotective agent to reduce HT in our model. Previous studies demonstrated that 12/15-LOX is upregulated in neurons and endothelial cells in the peri-infarct region after ischemic stroke and thereby appearing to play a significant role in the disruption of the blood brain barrier (BBB) seen after stroke ${ }^{24,25}$. Accumulating evidence implies that an increased permeability of the BBB after ischemia is one of the 
major causes of $\mathrm{HT}$ and edema formation resulting in the expansion of the damaged tissue beyond the infarct core ${ }^{26}$. 12/15-LOX inhibition or knockout was previously shown to reduce the loss of endothelial tight junction protein claudin-5 and the leakage of IgG after transient ischemia resulting in reduced infarct sizes and less hemorrhages seen in various models ${ }^{24,25}$. We therefore studied the role of 12/15-LOX in ASA+CPG mice in more detail and aimed to explore whether its inhibition is capable to reduce HT in our model.

\subsection{Methods}

The principal prerequisite of the study was to establish an experimental stroke model of HT under DAPT following tPA thrombolysis in mice. Main features of the model were the possibility to measure the platelet function and its use as a platform for investigating the mechanisms involved in HT and more importantly, for testing pharmacological approaches minimizing the hemorrhagic complications. While detailed explanations of the employed methods can be found in the publications ${ }^{27,28}$, a short overview will be provided in the following.

In our model, mice were fed with ASA+CPG diluted in drinking water (ASA $0.4 \mathrm{mg} / \mathrm{mL}$, CPG $0.15 \mathrm{mg} / \mathrm{mL}$ ) supplied ad libitum for $72 \mathrm{~h}$. If platelet function tests were performed, this was done at the end of this pretreatment period. To do so, venous blood $(10 \mu \mathrm{l})$ was collected from the left jugular vein and the platelet function was measured in vitro using a flow cytometry-based assay. Mice were then subjected to $2 \mathrm{~h}$ transient middle cerebral artery occlusion (tMCAO) followed by TPA administration if indicated. 24h later, standard tail bleeding tests may be conducted, and mice were sacrificed to quantify HT.

The in vitro platelet function testing was based on platelet expression of CD41 and CD62P: While CD41 was used to distinguish platelets from other blood cells ${ }^{29}$; CD62P was used to detect activated platelets, since CD62P is usually located in the a-granule membrane and only translocates to the plasma membrane upon platelet activation ${ }^{30}$. By detecting the co-expression of the antigens following thrombin stimulation, we gained an individual platelet activation rate for each single mouse. A high activation rate (indicated by increased CD62P expression) demonstrated good platelet function, whereas a lower 
activation rate indicated impaired platelet function and thus efficient antiplatelet treatment.

For the MCAO, a 6-0 silicone-coated monofilament was introduced into the right internal carotid artery until the tip occluded the ostium of the MCA. $2 \mathrm{~h}$ after the onset of ischemia, the filament was withdrawn to initiate reperfusion, and $62.5 \mu \mathrm{L}$ of tPA $(4 \mathrm{mg} / \mathrm{ml}$, final $10 \mathrm{mg} / \mathrm{kg} \mathrm{BW}$ ) were given by intravenous infusion into the right jugular vein using a perfusion pump.

The establishing of the model itself, consisted of a series comparing the frequency and characteristics of occurring HT between different treatment groups. Mice were therefore randomly allocated to 4 groups. Group 1 served as controls and received neither $A S A+C P G$ pretreatment nor post-stroke tPA. Group 2 received $A S A+C P G$ but no poststroke tPA. Group 3 received post-stroke tPA but no ASA+CPG pretreatment. Group 4 received both $A S A+C P G$ pretreatment and post-stroke tPA.

For low dose tPA treatment at $6.67 \mathrm{mg} / \mathrm{kg}$, analogous to the ENCHANTED trial but adjusted for the rodent metabolism, tPA was dissolved to $2.67 \mathrm{mg} / \mathrm{ml}$.

In yet unpublished experiments, we next compared $\mathrm{HT}$ development in wildtype and LOX-KO mice. Here, all mice were subjected to $3 d A S A+C P G$ pretreatment followed by $2 \mathrm{~h} \mathrm{MCAO}$ and tPA application. The occurrence of HT was rated and morphological features studied. We next investigated the pharmacological inhibition of 12/15-LOX with ML351 in wildtype mice. The 12/15-LOX inhibitor ML351 $(50 \mathrm{mg} / \mathrm{kg})$ or its vehicle $(60 \mu \mathrm{l}$ DMSO) was injected intraperitoneally at the timepoint of reperfusion. We continued with complementary histological studies determining key contributors to the mechanism of HT in this model, which up to date haven't been fully completed.

All experiments conformed to a Massachusetts General Hospital approved protocol in accordance with the National Institute of Health's guide for the care and use of laboratory animals. Limiting variabilities due to sex differences, only male animals were used, and the investigators performing surgeries and evaluating data were blinded to the treatment groups. 


\subsection{Results and discussion}

The results of this study were published in "Frontiers in Neurology" under the title "Measurement of platelet function in an experimental stroke model with Aspirin and Clopidogrel treatment" in February 2020, in "Stroke" under the title "Dual antiplatelet therapy increases hemorrhagic transformation following thrombolytic treatment in experimental stroke" in August 2019 and have been discussed in "Neural regeneration research" under the title "Thrombolysis in acute stroke under dual antiplatelet therapy: Perspectives arising from translational studies" in July 2020. The results of the experiments investigating the 12/15-LOX pathway have not been published up to date.

\section{Assessment of platelet function}

To investigate the mechanism underlying $\mathrm{HT}$ in ischemic stroke under DAPT and IPA thrombolysis, an animal model had to be established. The prerequisite for this was the assessment of antithrombotic effects of DAPT in mice. We therefore established an in vitro test of platelet function employing FACS analysis of platelet activation markers. We first investigated platelet function separately in a subgroup of 15 mice (8 ASA+CPG pretreated mice vs. 7 untreated controls) not subjected to experimental stroke. Platelet function was assessed in vitro using flow cytometry and in vivo with standard tail bleeding tests at the end of 3 days pretreatment. Here, platelet activation rates in ASA+CPG mice $(n=8)$ were reduced by $26.7 \pm 4.7 \%(p<0.0001)$ compared to control mice $(n=7)$ while bleeding volumes were increased by $5.1 \pm 1.0 \mu l(p=0.0002)$ compared to controls. Platelet activation rates measured in vitro correlated inversely with bleeding volumes in tail bleeding tests $(r=-0.8, p=0.0004, n=15$, Zheng and Lieschke et al., Stroke, 2019).

\section{Implementation of platelet function testing into experimental stroke}

We next incorporated the measurement of platelet function into our experimental stroke protocols, aiming to investigate whether and how platelet function contributes to IPA associated HT. After 3 days of pretreatment, animals were first subjected to in vitro testing of platelet function, and subsequently to $2 \mathrm{~h} \mathrm{tMCAO}$ with tPA treatment. $24 \mathrm{~h}$ after onset of ischemia, tail bleeding tests were performed, followed by sacrifice and $\mathrm{HT}$ 
assessment. We found pre-stroke platelet activation rates in ASA+CPG treated mice $(n=15)$ to be reduced by $40.6 \pm 4.2 \mu \mathrm{l}(p<0.0001)$ compared to control mice $(n=12)$.

Investigating the effect of platelet function on $\mathrm{HT}$ development, we found that $\mathrm{HT}$ did not occur in mice that demonstrated beforehand high activation rates upon in vitro stimulation with thrombin (CD62P expression $>80 \%$ ), whereas mice showing reduced platelet activation rates (CD62P expression $<80 \%$ ) were at higher risk for $\mathrm{HT}$ development (CD62P expression $>80 \%$ : 0.9 $\pm 0.3 \mathrm{~mm} 2$; CD62P expression $<80 \%$ : 10.8 $\pm 4.4 \mathrm{~mm} 2, p=0.0335$, Lieschke et al, Frontiers in Neurology, 2020).

\section{Characterization of HT in ASA+CPG model}

Next, we aimed to describe the observed $\mathrm{HT}$ occurring after ASA+CPG and thrombolytic treatment in more detail. We characterized 1) HT following MCAO in controls ( $n=10) ; 2)$ $H T$ following MCAO in ASA+CPG pretreated mice $(n=9) ; 3) H T$ following MCAO and TPA treatment in control mice ( $n=7)$; and 4) $\mathrm{HT}$ following MCAO+tPA in ASA+CPG pretreated mice $(n=7)$. We found significantly increased hemorrhage following MCAO+tPA in ASA $+C P G$ pretreated mice (increased by $18.89 \pm 4.95 \mathrm{~mm}^{2}$ compared to MCAO-only mice, $p=0.0042$ and increased by $18.86 \pm 5.36 \mathrm{~mm}^{2}$ compared to MCAO+tPA mice, $p=0.0045) . A S A+C P G$ pretreatment prior to MCAO without tPA increased HT nonsignificantly (by $8.0 \pm 4.6 \mathrm{~mm}^{2}, p=0.3265$ ). Controls treated with and without tPA, showed only very few hemorrhages. Ischemic lesion size did not differ between groups $(p=0.1429)$. We found $A S A+C P G$ prior to $2 \mathrm{~h}$ tMCAO and tPA treatment to be a sufficient model of HT in ischemic stroke (Zheng and Lieschke et al., Stroke, 2019). The model can be used to further identify molecular contributors to HT in the context of mechanistic studies or to develop therapeutic approaches, testing strategies to limit HT.

\section{Encountering HT by the use of low-dose tPA}

As a first clinical approach to reduce $\mathrm{HT}$ following MCAO and TPA treatment in $A S A+C P G$ mice, we decreased the dosage of tPA used in our model. Imitating the low dose approach employed in the ENCHANTED trial, we compared HT following MCAO and low dose tPA treatment in control and ASA+CPG mice. Low dose tPA was not sufficient to reduce $H T$ in $A S A+C P G$ treated mice (HT in ASA+CPG mice was still 
increased by $19.3 \pm 5.4 \mathrm{~mm}^{2}, p=0.001$, Zheng and Lieschke et al., Stroke, 2019). Since the IPA pharmacodynamics and kinetics in a mouse differ greatly from humans, the transferability to the clinical setting would have been disputable at this point anyway. In addition, there have been many clinical studies on this topic in the past, which is why we never intended and were not capable to make any clinical specifications from the results of our experiment. Nonetheless, this experiment was primarily important to demonstrate that our model is suitable for testing therapies. We successfully demonstrated the feasibility of such modifying experiments to our model.

\section{2/15-LOX Inhibition or knockout reduced HT in ASA+CPG model}

Another strategy to reduce HT is to interfere LOX-dependent cell signaling in the ischemic brain ${ }^{31,32}$. We first investigated $\mathrm{HT}$ rates after ASA+CPG pretreatment, MCAO and tPA infusion in LOX-KO compared to WT mice. Only 2 out of 7 LOX-KO showed significant HT compared to 5 out of 9 WT mice with HT (Table1).

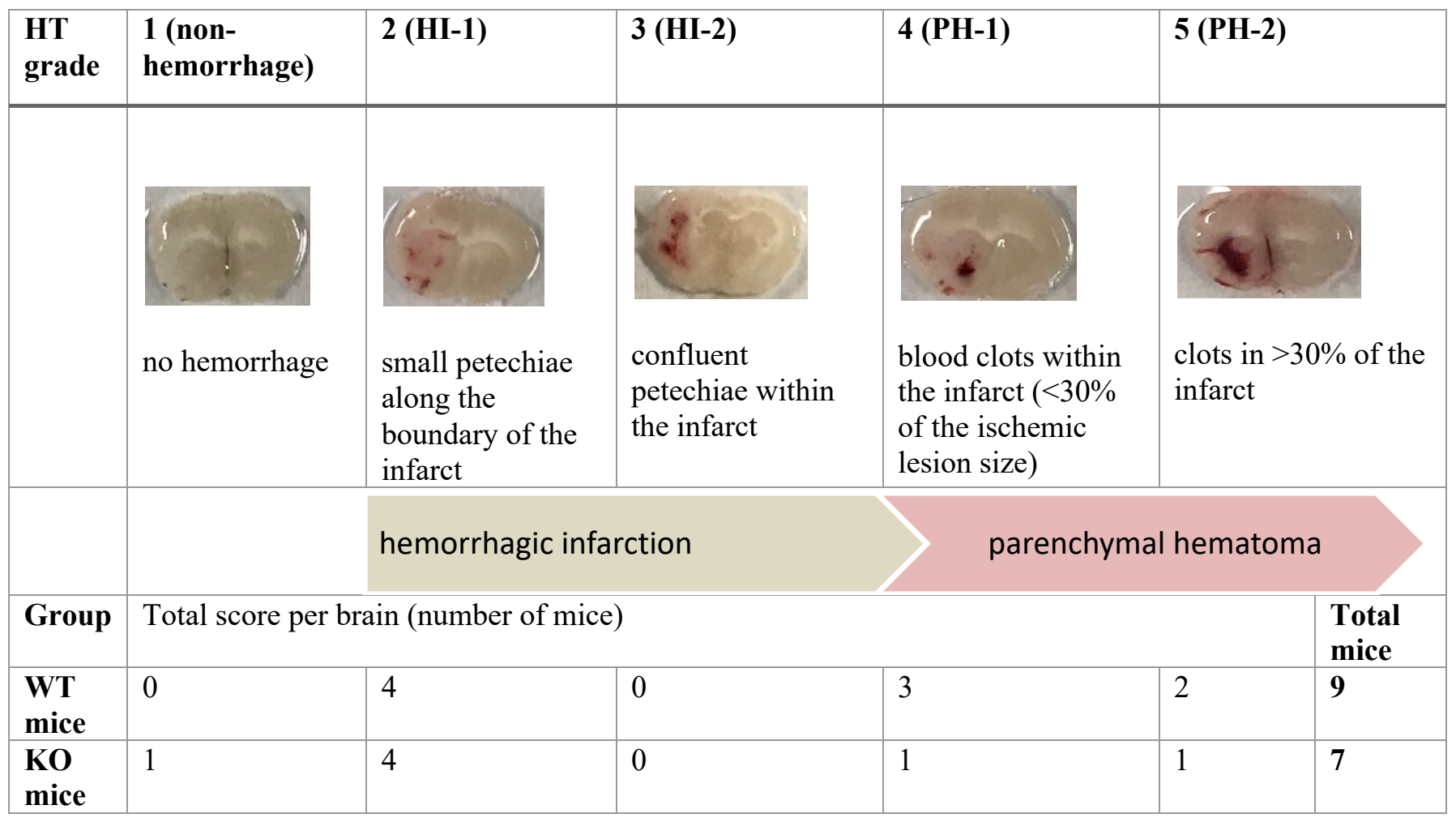

Table 1: $\mathrm{HI}=$ hemorrhagic infarction, $\mathrm{PH}=$ parenchymal hematoma, $\mathrm{WT}=$ wildtype, $\mathrm{KO}=$ knockout

Next, we tried to pharmacologically inhibit the LOX-enzyme using ML351. Therefore, ASA+CPG mice were subjected to MCAO and tPA treatment followed by ML351 
$(50 \mathrm{mg} / \mathrm{kg})$ or vehicle $(60 \mu \mathrm{l}$ DMSO) injection intraperitoneally at the time point of reperfusion. Succeeding in sufficiently limiting HT using LOX-inhibition with ML351, HT was significantly reduced by $7.3 \pm 3.0 \mathrm{~mm}^{2}$ ( $p=0.0004$, DMSO: $n=11$; ML351: $n=12$ ). Complementary histological studies -designed as a proof of concept study- were added in order to identify molecular contributors to the mechanism of HT. To identify the LOXexpressing cells, co-localization studies were conducted. By confocal microscopy, we could confirm that the LOX-signal derived endothelial cells (CD31 positive cells) (Figure 2; red: CD31, green: LOX, blue: DAPI for nuclei).

A

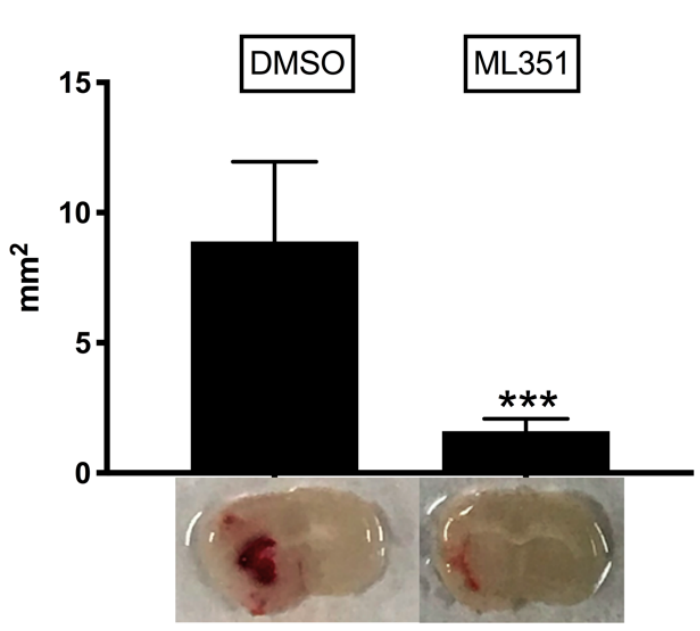

B

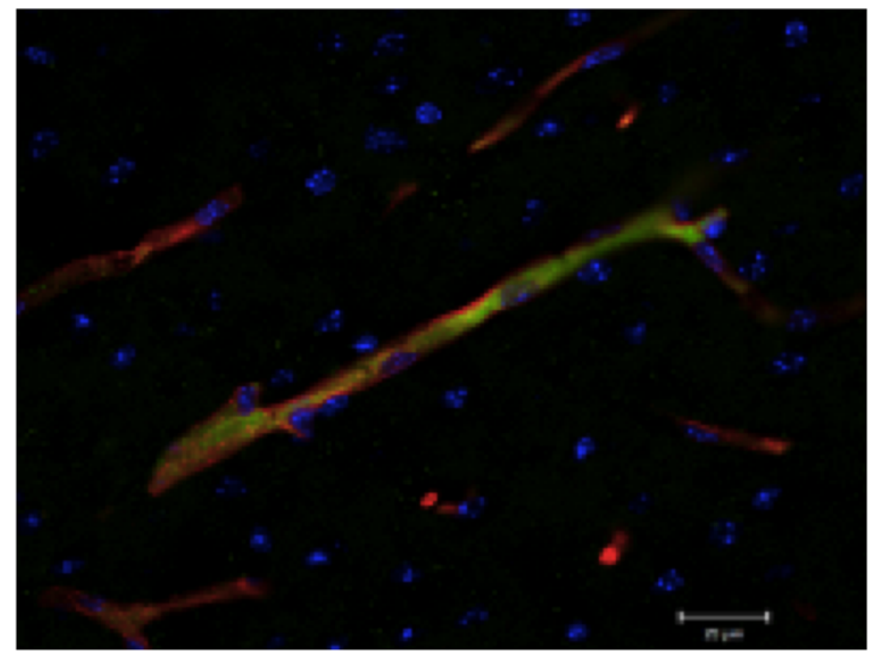

Figure $1 \mathrm{~A} H T$ assessment in brain sections $24 \mathrm{~h}$ after MCAO+tPA in $A S A+C P G$ mice treated with vehicle (DMSO: $\left.8.9 \pm 3.1 \mathrm{~mm}^{2}, n=11\right)$ or ML351 $\left(1.6 \pm 0.5 \mathrm{~mm}^{2}, n=12\right)$. B Exemplary picture immunofluorescence for CD31 in red, 12/15-LOX in green and DAPI for nuclei in blue in $A S A+C P G$ mice following $2 h M C A O$ and tPA treatment.

In summary, our findings document several aspects:

1. Despite some variability in the response to the antiplatelet pretreatment seen in our platelet function tests and in contrast to what is known from patients, antiplatelet resistance did not exist in the C57BI6 mice used in our study. Considering that the descendants of this inbred mouse strain are presumed to be genetically identical, this finding was somewhat of expected but has not been clear in advance and thus needed to be controlled for. We are confident that we sufficiently demonstrated the implementation of flow cytometry-based platelet function testing prior to and after MCAO surgery. Furthermore all treated mice exhibited platelet activation rates lower than $80 \%$. 
Together with the significantly altered risk of HT in these mice, we could conclude that impaired platelet function increased the risk of HT in our model.

2. Confirming various clinical studies, DAPT with $A S A+C P G$ prior to experimental stroke increased the risk of HT significantly, which points to the question whether the risk that comes with it (of possibly dangerous neurological deterioration) can be outweighed by tPA benefits. Most clinical trials captured neurologic outcome and mortality at 3 months only. However, long term consequences that occur several years later have not been studied yet. The same clinical studies eventually led to the elimination of DAPT as a contraindication for IPA treatment, in order to broaden the patient population eligible for tPA despite the knowledge about possible effects on vascular cognitive impairment and dementia. At this point, strategies increasing the safety of tPA while maintaining or even increasing tPA benefits of restoring closed vessels are of utmost warrant. A promising approach to prevent $\mathrm{HT}$ and reduce the risk of acute complications but also long-term consequences is the early stabilization of the BBB, which leads us to a third important aspect of our model.

3. LOX-inhibition using ML351 was shown to reduce HT in ASA+CPG mice following ischemic stroke and tPA thrombolysis. This finding goes in line with recent studies that identified the enzyme 12/15-LOX being upregulated in neurons and vascular endothelial cells in the peri-infarct region after experimental stroke. Following ischemic stroke, 12/15-LOX was proven to be involved in neuronal cell death and vessel injury via different molecular pathways including oxidative glutamate toxicity and membrane attacking of organelles, especially mitochondria. Further studies showed that LOX knockout mice were protected from ischemia and developed less edema following experimental stroke compared to wild type mice, indicating a better integrity of their $\mathrm{BBB}^{24}$. The pharmacological inhibition of 12/15-LOX with different agents such as Baicalein, LOXBlock-1 or ML351 reduced ischemic injury and BBB disruption and thus effectively protected against $\mathrm{HT}^{25,31-33}$. It is clear that subsequent studies must follow on these findings, further elucidating the role of 12/15-LOX in BBB stabilization, especially in the context of thrombolysis under antiplatelet pretreatment. 
As we have already mentioned in our publications, especially in our Perspective article, there are limits to our work. Like all animal studies, some general key differences that narrow down the comparability to patients have to be addressed. While DAPT in patients is usually initiated following a first stroke or myocardial infarction, the initiation and duration of DAPT in our model was set artificially. Furthermore, stroke patients regularly suffer from several comorbidities resulting in hemorrhagic conversion typically occurring in elderly, comorbid patients ${ }^{9,10}$. In contrast to that, the animals used in our study were young and healthy with all experiments being conducted under controlled environmental and standardized conditions. A last but major concern is that we (similarly to the clinical studies) looked at one timepoint only. Hence, the model would needed to be adapted for long-term outcome studies in the future. However, using the current protocol, a high mortality must be expected.

In summary, while the use of DAPT in acute stroke patients is expected to further increase, it becomes crucial to optimize the complication management towards improved security. A translational approach can be beneficial in helping to understand the pathophysiology of HT under these circumstances. We succeeded in establishing an experimental stroke model of tPA-associated HT under DAPT, which in addition provides a sufficient platform for testing therapeutical approaches to encounter hemorrhagic complications. However, the questions surrounding long term neurological outcomes and vascular cognitive impairment following $\mathrm{HT}$ are not yet completely resolved. Promising candidates like lipoxygenase inhibitors may represent sufficient approaches that should be further evaluated in future studies. 


\section{5 Übersicht der Publikationen}

- Franziska Lieschke, Yi Zheng, Jan Hendrik Schaefer, Klaus van Leyen, Christian Foerch; Measurement of platelet function in an experimental stroke model with Aspirin and Clopidogrel treatment; Frontiers in Neurology; 11:85; 19; 2020

- Yi Zheng*, Franziska Lieschke*, Jan Hendrik Schaefer, Xiaoying Wang, Christian Foerch and Klaus van Leyen; Dual antiplatelet therapy increases hemorrhagic transformation following thrombolytic treatment in experimental stroke; Stroke; 50; 3650-3653; 2019 *first shared

- Franziska Lieschke, Yi Zheng, Christian Foerch, Klaus van Leyen; Thrombolysis in acute stroke under dual antiplatelet therapy: Perspectives arising from translational studies; Neural Regeneration Research; 16:1,1-2; 2020 


\section{Darstellung des eigenen Anteils an den einzelnen Publikationen}

\subsection{Author contribution in "Measurement of platelet function in an experimental}

stroke model with Aspirin and Clopidogrel treatment"

$\mathrm{FL}, \mathrm{CF}$ and $\mathrm{KvL}$ conceived the idea, designed the model and analyzed the data. FL carried out the experiments and performed the measurements. $Y Z$ helped with the MCAO surgery. FL processed the experimental data, performed the statistical analysis, drafted the manuscript and designed the figures. JHS aided in interpreting the results. $\mathrm{KvL}$ and CF supervised the work. CF made critical revision of the manuscript for important intellectual content. All authors discussed the results and commented on the manuscript.

\subsection{Author contribution in "Dual antiplatelet therapy increases hemorrhagic transformation following thrombolytic treatment in experimental stroke"} $\mathrm{CF}$ conceived the original idea. $\mathrm{KvL}, \mathrm{YZ}$ and $\mathrm{FL}$ designed the experiments. $\mathrm{FL}$ and $\mathrm{YZ}$ carried out the experiments and acquired the data. FL processed the data, performed statistical analysis and interpreted the data with the help of KvL. JHS and XW aided in interpreting the results. FL took the lead in writing the manuscript and designed the figures. CF made critical revision of the manuscript for important intellectual content. All authors provided critical feedback and helped shape the research, analysis and manuscript.

\subsection{Author contribution in "Thrombolysis in acute stroke under dual antiplatelet therapy: Perspectives arising from translational studies"}

$\mathrm{KvL}$ conceived the original idea for this perspective article. KvL, CF and FL together designed the manuscript draft. FL conducted the literature review and took the lead in writing the manuscript and designed the figure. All authors provided critical feedback and helped to shape the article. 
7 Manuskript "Measurement of platelet function in an experimental stroke model with Aspirin and Clopidogrel treatment" 
OPEN ACCESS

Edited by: Simone Beretta,

San Gerardo Hospital, Italy

Reviewed by:

Barbara Casolla,

Centre Hospitalier Regional et

Universitaire de Lille, France Luigi Sironi,

University of Milan, Italy

*Correspondence:

Franziska Lieschke

franziska.lieschke@

stud.uni-frankfurt.de

Specialty section: This article was submitted to

Stroke,

a section of the journal

Frontiers in Neurology

Received: 01 November 2019

Accepted: 23 January 2020 Published: 11 February 2020

Citation: Lieschke F, Zheng Y, Schaefer JH, van Leyen K and Foerch C (2020) Measurement of Platelet Function in an Experimental Stroke Model With Aspirin and Clopidogrel Treatment.

Front. Neurol. 11:85. doi: 10.3389/fneur.2020.00085

\section{Measurement of Platelet Function in an Experimental Stroke Model With Aspirin and Clopidogrel Treatment}

\author{
Franziska Lieschke ${ }^{1,2 *}$, Yi Zheng ${ }^{1}$, Jan Hendrik Schaefer ${ }^{2}$, Klaus van Leyen ${ }^{1}$ and \\ Christian Foerch ${ }^{2}$
}

'Neuroprotection Research Laboratory, Department of Radiology and Neurology, Massachusetts General Hospital, Harvard Medical School, Charlestown, MA, United States, ${ }^{2}$ Department of Neurology, University Hospital Frankfurt Goethe-University, Frankfurt am Main, Germany

Dual antiplatelet treatment (DAPT) increases the risk of tPA-associated hemorrhagic transformation $(\mathrm{HT})$ in ischemic stroke. To investigate the effects of DAPT in rodents, reliable indicators of platelet function utilizing a minimally invasive procedure are required. We here established a fluorescence-based assay to monitor DAPT efficiency in a mouse model of ischemic stroke with HT. Male C57/BL6 mice were fed with aspirin and clopidogrel (ASA+CPG). Venous blood was collected, stimulated with thrombin, labeled with anti-CD41-FITC and anti-CD62P-PE, and analyzed by flow cytometry. Subsequently, animals were subjected to experimental stroke and tail bleeding tests. $\mathrm{HT}$ was quantified using $\mathrm{NIH}$ ImageJ software. In ASA+CPG mice, the platelet activation marker CD62P was reduced by $40.6 \pm 4.2 \%(p<0.0001)$ compared to controls. In vitro platelet function correlated inversely with tail bleeding tests $(r=-0.8, p=0.0033$, $n=12)$. Twenty-four hours after drug withdrawal, platelet activation rates in ASA+CPG mice were still reduced by $20.2 \pm 4.1 \%(p=0.0026)$ compared to controls, while tail bleeding volumes were increased by $4.0 \pm 1.4 \mu \mathrm{l}(p=0.004)$. Conventional tests using light transmission aggregometry require large amounts of blood and thus cannot be used in experimental stroke studies. In contrast, flow cytometry is a highly sensitive method that utilizes small volumes and can easily be incorporated into the experimental stroke workflow. Our test can be used to monitor the inhibitory effects of DAPT in mice. Reduced platelet activation is indicative of an increased risk for tPA-associated cerebral hemorrhage following experimental stroke. The test can be applied to individual animals and implemented flexibly prior and subsequent to experimental stroke.

Keywords: dual antiplatelet therapy, aspirin, clopidogrel, flow cytometry, CD62P, CD41, hemorrhagic transformation, MCAO

\section{INTRODUCTION}

The use of dual antiplatelet treatment (DAPT) in the acute phase of stroke is becoming increasingly common $(1,2)$. Apart from patients prescribed DAPT for other indications (3), this includes the application of DAPT in patients with transient ischemic attacks and minor strokes, as well as DAPT treatment during acute revascularization procedures $(4,5)$. By irreversibly impairing platelet function, DAPT increases the risk of hemorrhagic complications after thrombolysis with tPA (6-8). 
Current European and American guidelines do not recommend to perform platelet function tests during the acute phase of ischemic stroke $(9,10)$. Although platelet function testing has become widely accessible with the use of point of care devices, investigations whether patients could potentially benefit are still lacking. On the other hand, rapid testing of the platele count is a well-established standard in the treatment of stroke. Here, low platelet counts are excluded from tPA treatment due to the significantly increased risk of hemorrhagic transformation (HT) in platelet depleted patients (11). However, the question of whether and how platelet function contributes to tPA-associated HT has not been answered to date.

To address this gap of knowledge, we recently established a model of tPA-associated hemorrhagic transformation (HT) in mice pretreated with Aspirin and Clopidogrel [ASA+CPG (12)]. While establishing antiplatelets in rodents, the individual hemostatic status of the single mouse becomes relevant. We therefore looked for a simple platelet function test to check for individual drug response.

Conventional platelet function tests like light transmission aggregometry (LTA) require significant volumes of blood (13), which means either collecting a lethal amount of blood from one mouse or collecting and pooling blood from different animals (14). As a result LTA is too invasive to be used as a measure of platelet status at the time of experimental stroke surgery. A simple-to-conduct but unspecific method is the tail bleeding test which illustrates platelet adhesion in vivo and corresponds to the bleeding time test formerly used in patients $(15,16)$. The principle underlying this test is that platelet function directly affects primary hemostasis after tissue damage, resulting in prolonged bleeding time (time to complete cessation of the bleeding) and increased blood volumes during testing in mice. It can only be done once at the end of an experiment, and precludes the evaluation of drug efficacy in advance and repeated measurements. Accordingly, methods are required that utilize small sample volumes. Flow cytometry is a highly sensitive method requiring only small volumes of blood. Platelet activation assays based on flow cytometry have been introduced (17-19) but at present they are not widely used and have not been tested in the context of experimental stroke studies.

The aim of this study was to demonstrate the feasibility of incorporating flow cytometry-based platelet function testing in a mouse model of DAPT followed by an ischemic stroke and tPA infusion. In addition to monitoring the efficacy of antiplatelet therapy, we also sought to further investigate the impact of platelet function on the development of HT in order to predict bleeding risks and to define inclusion and exclusion criteria for subsequent experiments.

\section{MATERIALS AND METHODS}

\section{Animals and Experimental Design}

In total 28 male C57/B6 mice (Jackson, Bar Harbor, ME, USA) aged 9-10 weeks with a mean body weight of $26 \pm 2 \mathrm{~g}$ were used in this study. All experiments conformed to an institutionally approved protocol in accordance with the National Institute of Health's guide for the care and use of laboratory animals. We used exclusively male animals to limit variability due to sex differences. The operators performing surgical procedures and the investigators evaluating data were blinded to the treatment groups. At first, we assessed platelet function in vitro using ou flow cytometry-based assay (as explained below) in mice treated with ASA+CPG and in controls. Mice were then subjected to $2 \mathrm{~h}$ MCAO followed by tPA administration. Twenty-four hours later, standard tail bleeding tests were conducted $(14,20)$, and mice were sacrificed to quantify HT development. A second in vitro analysis of platelet function was performed at the end of the experiment in order to demonstrate the feasibility of monitoring treatment effects beyond drug withdrawal (Figure 1A).

\section{Antiplatelet Pretreatment}

Mice were allocated randomly to a treatment or control group. ASA (Bayer Health Care, Morristown, NJ, USA) and CPG (Dr. Reddy's Laboratories Ltd., Beverley, UK) diluted in drinking water (ASA $0.4 \mathrm{mg} / \mathrm{mL}$, CPG $0.15 \mathrm{mg} / \mathrm{mL}$ ) were supplied ad libitum for $72 \mathrm{~h}$. A water consumption of $15 \mathrm{ml} / 100 \mathrm{~g}$ per $24 \mathrm{~h}$ was assumed, providing an estimated daily intake of $60 \mathrm{mg} / \mathrm{kg}$ ASA and $22.5 \mathrm{mg} / \mathrm{kg}$ CPG per mouse. These dosages were selected based on previous experimental stroke studies $(14,21)$. Control mice received regular drinking water.

\section{Flow Cytometry Based Platelet Function Test}

In vitro platelet function testing was based on the platele expression of CD41 and CD62P. We used the platelet marker CD41 to distinguish platelets from other events. CD62P is usually located in the membrane of platelet $\alpha$-granules in the cytoplasm and only translocates to the plasma membrane after platelet activation (22). By detecting the surface coexpression of these antigens following thrombin treatment using a BD LSRII analyzer (Becton-Dickinson, San Jose, CA, USA), we gained an individual platelet activation rate for each single mouse. A high activation rate (indicated by increased CD62P expression) demonstrates sufficient platelet function, whereas a lower activation rate indicates impaired platelet function due to the partial inhibition of platelets, hence also serving as an indicator for an efficient anti-platelet treatment. Briefly, mice were anesthetized with isoflurane $(1.25-1.5 \%$ in a nitrous oxide/oxygen mixture with spontaneous respiration) Venous blood (10-20 $\mu \mathrm{l})$ was collected from the left jugular vein and given into sodium citrate (final $0.32 \%$, Sigma) to prevent unintended platelet activation and blood clotting. Five microliters of whole blood were diluted in thirty microliters of PBS containing $0.32 \%$ sodium citrate. Fifteen microliters of vehicle or agonist solution were added, where the vehicle was composed of PBS containing $0.32 \%$ sodium citrate, and the agonist solution consisted of thrombin (final $2 \mu / \mathrm{ml}$ ) supplemented with $10 \mathrm{mM}$ GPRP (final $2.5 \mathrm{mM}$ ) and $6 \mathrm{mM}$ $\mathrm{CaCl} 2$. The samples were then incubated shaking at $37^{\circ} \mathrm{C}$ for $5 \mathrm{~min}$. Mouse blood was incubated with 1:100 dilution of CD41FITC and CD62P-PE monoclonal antibodies (BD Biosciences and eBioscience ${ }^{\mathrm{TM}}$, respectively) for $15 \mathrm{~min}$ at room temperature in the dark. After staining, samples were fixed with $650 \mu \mathrm{l}$ of fixative solution containing $0.1 \%$ formalin, $0.1 \%$ dextrose, 


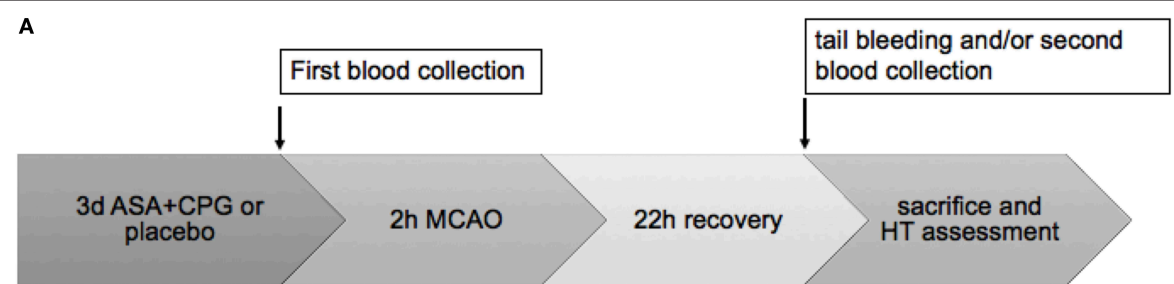

B

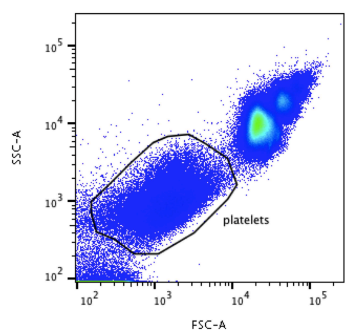

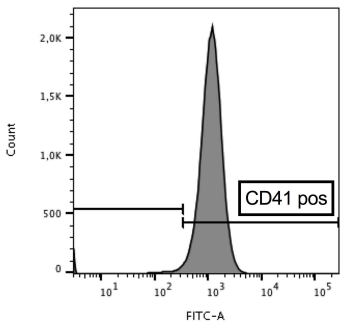

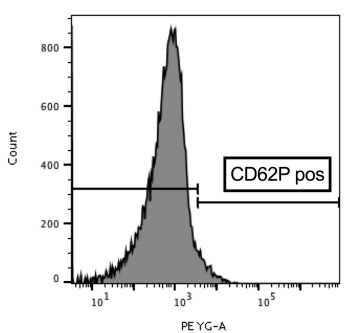

FIGURE 1 | (A) Timeline diagram of the experimental procedures: platelet function in control and ASA+CPG mice was tested in vitro using flow cytometry at the end of 3 days pretreatment. Mice were subjected to $2 \mathrm{~h} \mathrm{MCAO}$ and tPA administration. Twenty-two hours later, tail bleeding tests and a second flow cytometry analysis were performed, followed by sacrifice and histological assessment of hemorrhage. (B-D) Gating strategy: Ungated whole blood (B). Gated cells scored high for platelet identification marker FITC-CD41 (C) and low for the platelet activation marker PE-CD62P (D), consistent with the properties of resting platelets (Analysis performed with FlowJo).

and $0.2 \%$ BSA in PBS. Labeled, diluted and fixed samples were analyzed. Platelets were gated based on their characteristic forward and side scatter properties (Figure 1B), as well as for antiplatelet immunoreactivity for CD41 (Figure 1C). The third gate was set on a positive staining with monoclonal antibody CD62P-PE (Figure 1D). Analyses were performed with BD FACS DIVA software (BD Biosciences) and FloJo (v10).

\section{MCAO}

Animals were anesthetized, and a 6-0 silicone-coated monofilament was introduced into the right internal carotid artery until the tip occluded the ostium of the MCA. Regional cerebral blood flow was monitored by laser doppler flowmetry with the use of a probe fixed to the intact skull above the territory of the right MCA. Rectal temperature was maintained between 36.5 and $37^{\circ} \mathrm{C}$ with a heating pad. After surgery, animals were allowed to recover from anesthesia. Hundred and twenty minutes after MCAO, the filament was withdrawn to initiate reperfusion, and $62.5 \mu \mathrm{L}$ of tPA $(4 \mathrm{mg} / \mathrm{ml}$, final $10 \mathrm{mg} / \mathrm{kg}$ BW) were given by intravenous infusion into the right jugular vein over $15 \mathrm{~min}$ using a perfusion pump. $0.1 \mathrm{mg} / \mathrm{kg}$ BW buprenorphine hydrochloride (Buprenex $^{\circledR}$, Reckitt Benckiser Healthcare Ltd, UK) were administered at the end of all procedures.

\section{Standard Tail Bleeding}

To control for confounders, we first assessed the body temperature: Hypothermic mice were excluded, while normothermic mice were anesthetized and placed on a heating pad in prone position. A distal $5 \mathrm{~mm}$ segment of the tail was amputated with a razor blade. Tails were immediately inserted into microtubes containing 1 microliter saline placed in a water bath pre-warmed to $37^{\circ} \mathrm{C}$. After $3 \mathrm{~min}$, the tail was removed from the microtube, and hemostatic measures were taken by electro-cauterization using Bovie ${ }^{\circledR}$. The microtube was vortexed, and ultrasound was applied for $15 \mathrm{~s}$ to lyse erythrocyte cell membranes. $3 \times 100 \mu \mathrm{L}$ were transferred to a 96 well plate containing $40 \mu \mathrm{L}$ of Drabkin's reagent and incubated for $15 \mathrm{~min}$. Absorption rates at $540 \mathrm{~nm}$ were determined using a SpectraMax M5 photometer. Bleeding volumes were calculated using a standard curve $(14,20,23)$.

\section{HT Determination}

For HT measurement in the brain, mice were lethally anesthetized and perfused transcardially with saline. The brains were removed and sectioned into $1 \mathrm{~mm}$ thick slices and photographed. HT was assessed as red areas in brain sections, outlined and measured using ImageJ. Hemorrhages were classified according to the ECASS II morphologic definitions (24, $25)$ adapted to animal models as used in previous publications $(12,26,27)$. Therefore, every section was individually scored on a 5 point ordinal scale $(1=$ no HT; $2=$ hemorrhagic infarction type $1 ; 3=$ hemorrhagic infarction type $2 ; 4=$ parenchymal hemorrhage type $1 ; 5=$ parenchymal hemorrhage type 2 ) and 
an overall grade for every brain was determined according to the highest grade occurring among the sections.

\section{Exclusion Criteria}

Death within the $22 \mathrm{~h}$ recovery period led to exclusion from further assessment. Post-stroke tail bleeding tests were not performed in surviving animals when the general condition was too severe (indicated by a low body temperature $\left(<32^{\circ} \mathrm{C}\right)$ and slow breathing rate, for details please see Supplementary Material).

\section{Post-stroke Flow Cytometry Analysis of Platelet Function}

Post-stroke flow cytometry analysis was performed with blood collected from 5 randomly chosen control mice and 3 ASA +CPG treated mice by cardiac puncture at the time point of sacrifice and conducted as described above.

\section{Statistics and Data Analysis}

Data is presented as mean \pm SEM. Values were tested for Gaussian distribution with D'Agostino-Pearson omnibus normality test and Kolmogorov test. Statistical significance was determined for two group comparisons with Welch's $t$-test or Mann-Whitney test, and data sets were considered different if $p<0.05$. Correlations were calculated with Spearman's test. All statistics were performed using Prism 7 graphpad software.

\section{RESULTS}

\section{Pre-stroke Platelet Function Testing}

In control mice $(n=12)$ platelet pre-activation in unstimulated samples was $3.6 \pm 2.0 \%$ vs. $2.0 \pm 0.7 \%$ in unstimulated blood obtained from ASA + CPG treated mice $(n=15, p=0.365$ Figure 2A). In vitro stimulation with thrombin platelet activation was $88.0 \pm 0.6 \%$ in controls compared to $47.5 \pm 3.7 \%$ in
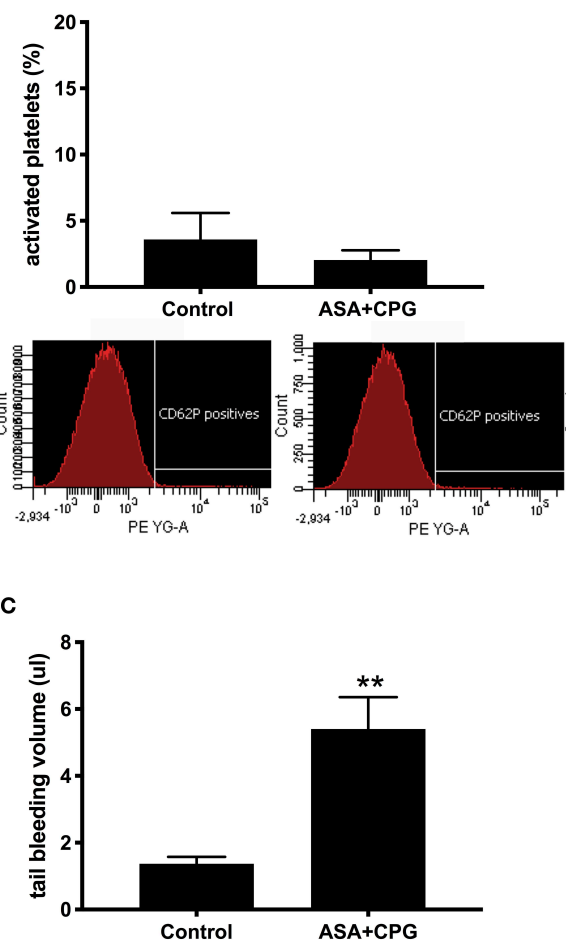

B
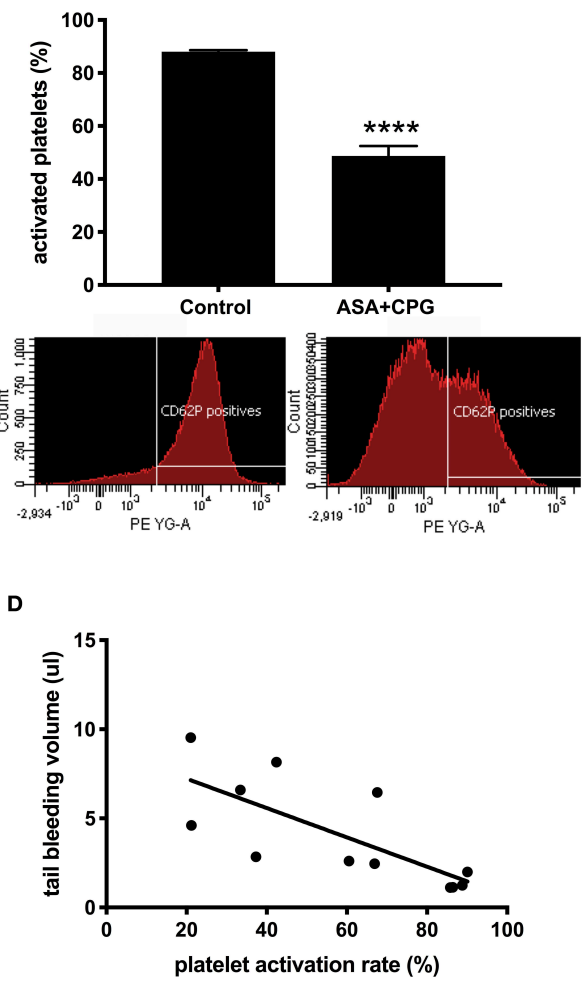

FIGURE 2 | (A) Platelet activation rates in unstimulated samples: Control: $3.6 \pm 2.0 \%, n=12$; ASA+CPG: $2.0 \pm 0.7 \%, n=15, p=0.3649$ with selected example images of fluorescence intensity for platelet activation marker anti-CD62P-PE in unstimulated blood samples (FACSDiva software). (B) Platelet activation rates in thrombin stimulated samples: Controls: $88.0 \pm 0.6 \%, n=12$; ASA+CPG: $47.5 \pm 3.8 \%, n=15, p<0.0001$, images of anti-CD62P-PE fluorescence intensity after in vitro thrombin stimulation. (C) Blood volumes in post-stroke tail bleeding testing: Controls: $1.4 \pm 0.2 \mu \mathrm{l} / 3 \mathrm{~min}, n=4$; ASA+CPG: $5.4 \pm 0.9 \mu \mathrm{l} / 3 \mathrm{~min}, n=8$, $p=0.004$. (D) Correlation of in vitro platelet function with in vivo tail bleeding volumes: Linear regression: $R^{2}=0.5518, y=-0.08175$ (95\% Cl: -0.134 to $\left.(-0.03)^{\star} X+8.846\right)$. Correlation: $r=-0.7902, p=0.0033, n=12 .{ }^{\star \star} p<0.01 ;{ }^{* \star *} p<0.0001$ 
ASA + CPG treated mice $(p<0.0001$, Figure 2B), indicating a partial platelet inhibition in these animals. Thus, we sufficiently demonstrated the in vitro detection of ASA+CPG drug effects in whole blood collected from mice following 3 days of oral drug administration

\section{Implementation Into Experimental Stroke}

Subsequently, we subjected all mice to $2 \mathrm{~h} \mathrm{MCAO}$ and tPA infusion, followed by a $22 \mathrm{~h}$ recovery period before performing tail bleeding tests (Figure 1A). During the recovery period, 4 control mice and 2 ASA+CPG treated mice died. We examined the deceased animals, focusing on intracerebral- or gastrointestinal bleeding or any other obvious hemorrhagic complication. Neither the ASA+CPG mice nor the control mice showed severe hemorrhages, suggesting that mortality was mainly related to the fairly severe ischemia induced by $2 \mathrm{~h}$ of MCAO. Tail bleeding volumes measured in 8 ASA+CPG treated mice were on average $5.4 \pm 0.9 \mu \mathrm{l}$ compared to 1.4 $\pm 0.2 \mu \mathrm{l}$ measured in 4 control mice $(p=0.004$, Figure $2 \mathrm{C}$ ) suggesting platelet inhibition was still effective $24 \mathrm{~h}$ after cessation of treatment.

In comparing the individual results of pre-stroke platelet function testing with post-stroke tail bleeding volumes (the standard in vivo measure of platelet function), we found that low platelet activation rates upon in vitro thrombin stimulation correlated significantly with increased blood loss in the tail bleeding test and vice versa $(r=-0.7902, p=0.0033, n=12$; Figure 2D), suggesting our method is feasible to depict platelet function in mice.

Investigating the effect of platelet function on HT development, we found that HT did not occur in mice that demonstrated beforehand high activation rates upon in vitro stimulation with thrombin (CD62P expression $>80 \%$ ), whereas mice showing reduced platelet activation rates $(\mathrm{CD} 62 \mathrm{P}$ expression $<80 \%$ ) were at higher risk for HT development (CD62P expression >80\%: $0.9 \pm 0.3 \mathrm{~mm}^{2}$; CD62P expression $<80 \%$ : $10.8 \pm 4.4 \mathrm{~mm}^{2}, p=0.0335$, Figure 3A). No hemorrhages were found remote from the infarct. The morphological classification of the HT types showed that $0 / 7$ control mice

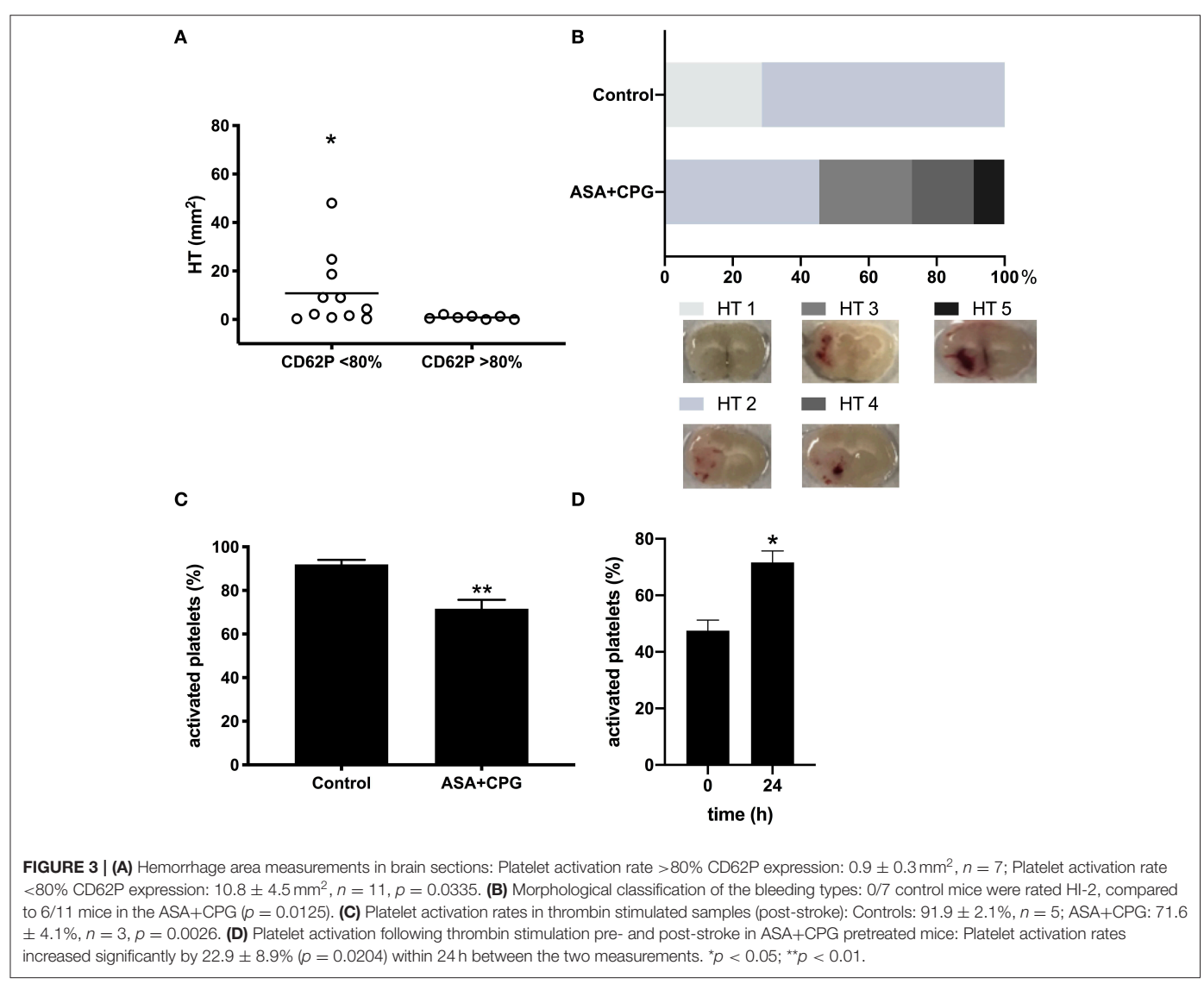


were rated HI-2, compared to $6 / 11$ mice in the ASA+CPG $(p=0.0125$, Figure 3B, Supplementary Table I).

\section{Post-stroke Platelet Function Testing}

In analogy to the post-stroke tail bleeding testing, we performed a second in vitro platelet function testing post-stroke in randomly selected mice at the time point of sacrifice. In ASA+CPG pretreated mice, platelet activation upon in-vitro thrombin stimulation $24 \mathrm{~h}$ after drug withdrawal was $71.6 \pm 4.1 \%$ compared to $91.9 \pm 2.1 \%$ in controls (Figure 3C, $p=0.0026$ ) Although the antiplatelet effect of ASA $+\mathrm{CPG}$ pretreatment was still detectable $24 \mathrm{~h}$ after stroke and drug withdrawal, platelet function in ASA+CPG pretreated mice already improved significantly compared to the platelet activation rates of the first in vitro testing (Figure 3D platelet activation rates in ASA+CPG mice pre-stroke $47.5 \pm 3.8 \%$ vs. $71.6 \pm 4.1 \%$ post-stroke). We here present the feasibility of repeated sampling within a stroke model using our flow cytometry-based platelet function assay.

\section{DISCUSSION}

With this study, we successfully developed a practical and straightforward method to test platelet function in vitro using flow cytometry, and we applied this assay to ASA+CPG treated mice in the context of experimental stroke studies in order to monitor antithrombotic treatment efficacy. Furthermore, we demonstrated that our method can be implemented at different time points within the stroke model and that repeated measurements are also feasible. Our method can be used to identify animals that are at a higher risk for developing HT, in order to study the pathophysiology and to explore new therapeutic approaches.

Thus, far, tail bleeding has been the only measure that assesses platelet function in an individual mouse without the need to pool blood from different subjects (which is needed for LTA) However, when it comes to its implementation into stroke models, this approach faces serious limitations. First, tail bleeding testing can only be performed at the end of an experiment before sacrifice due to a high risk of severe and uncontrolled bleeding. Secondly, the tail bleeding test is relatively unspecific (20). It can be affected by secondary hemostasis, blood pressure and body temperature. Another disadvantage is that mice cannot be tested repetitively, precluding dynamic measurements. In contrast, our flow cytometry based technique of platelet function analysis requires only $0.5-1 \%$ of the total blood volume of a mouse, allowing for repeated sampling.

We showed that there was no significant difference in platelet activation in unstimulated blood between ASA + CPG treated mice and control mice prior to stroke, which indicates that our samples were handled equally, resulting in acceptable preactivation rates. However, pre-activation rates in ASA+CPG treated mice were slightly reduced compared to controls, which is in line with the findings of Kassassir et al. (19), who demonstrated that pre-activation rates in mice intravenously treated with cangrelor (another ADP-receptor antagonist like CPG) were reduced compared to untreated controls (19).
As we had hypothesized, ASA+CPG treatment led to significantly reduced platelet activation rates upon in vitro stimulation with thrombin. These treatment effects occurred in a comparable range to previously reported results in humans (28), although relatively high treatment dosages (of $60 \mathrm{mg} / \mathrm{kg}$ ASA and $22.5 \mathrm{mg} / \mathrm{kg} \mathrm{CPG}$ ) were used. The faster metabolism of mice and different administration protocols (crushing and diluting tablets which are designed for enteric resorption in humans) may explain these comparable effects in spite of a higher absolute dose $(19,22,29,30)$. Ultimately, while there was some variability in the response, we did not identify any non-responders, and all ASA + CPG mice showed reduced platelet reactivity.

Accordingly, we demonstrated that the impaired platelet function after ASA+CPG pre-treatment is strongly correlated with higher tail bleeding volumes. Thus, our method can be used to identify mice with decreased platelet function. Based on this, cohorts with an overall increased risk of HT could be identified. However, HT prediction on an individual animal level remains difficult. Similar to humans, not every pretreated mouse developed HT following thrombolytic treatment, although mice that showed hemorrhages generally had lower activation rates. These findings are in line with previous attempts to better stratify the risk of tPA-associated HT in human patients $(7,31-36)$, which aimed to define risk scores and predictors for HT With only modest predictive power, those models failed to identify common key contributors. More research on pre-stroke platelet function and its impact on later HT development and neurological outcome may help to fill this gap of knowledge.

The current literature also revealed that despite the higher risk of $\mathrm{tPA}$-associated HT in patients on DAPT, mortality and neurologic outcomes did not differ from patients without DAPT; thus, the benefit of tPA seemed to outweigh its risk (37-39). In order to get a clearer picture, it may be useful to implement platelet function testing during the early phase of acute ischemic stroke through using flow cytometry-based assays or point of care devices, which have already replaced the previous standard screening methods for platelet dysfunction (40). Testing the platelet function rather than the platelet count could potentially make discussion about platelet threshold superfluous (41).

We also need to address the limitations of our study. In conventional aggregation assays, typically $\mathrm{ADP}$ is used to demonstrate CPG effects (32). ADP receptor activation in mice leads to the release of platelet dense granules but not to the release of alpha granules (14). We used CD62P which is only located in alpha granules; thus, ADP stimulation could not be illustrated using anti-CD62P. Another consideration addressing the flow cytometry test relates to our method of quantification. An accepted strategy to quantify platelet aggregation using flow cytometry is the determination of the loss of single platelet due to aggregation upon platelet activation (17, 18, 28, 42, 43) Since we were using two separate samples when comparing unstimulated vs. stimulated blood, we were unable to consistently detect and quantify the loss of single platelets in these samples. A complementary strategy to deal with these limitations for future studies is to use only one sample and repeat measurements before and after platelet stimulation. However, this would require the platelet count to be determined. Which implies another 
limitation to our study, since platelet function can be affected by platelet count $(44,45)$. Also, we have not tested platelet function following long-term treatment yet, in which other hemostatic factors besides platelets may also be affected. In addition, our study was designed as a single-center study at the Neuroprotection Research Laboratory (Massachusetts Genera Hospital), and needs to be confirmed by replication in other laboratories. A last but major concern is the validation of our flow cytometry assay by using tail bleeding. Since platelet function in vitro and in vivo may differ $(44,46,47)$, it is insufficient to base examinations on either in vitro or in vivo only. By combining the FACS analysis with tail bleeding, we intended to achieve a complementary insight into the hemostatic status of an individual mouse. As expected, tail bleeding volumes were increased in the pretreated mice $24 \mathrm{~h}$ after the ischemic event. At the same time, FACS analysis of blood from the same mice showed reduced platelet activation in the DAPT treated mice, and these results correlated well $(r=-0.7902, p$ $=0.0033$, Figure 2D). We also considered cross-validation by comparison with aggregometry, but decided against it because (a) Due to the large volume required for the aggregometer used in the MGH pathology core facility, we would have had to pool the blood of several mice, which practically could not be combined with a stroke model; (b) The procedure used to initiate platelet activation differs significantly from our approach. For example, the core facility uses ADP or arachidonic acid to activate the platelets in vitro, while we used thrombin in our study; (c) Measurements with aggregometers are manufacturer and laboratory specific, which implies a restricted comparability between centers. These limitations would have ruled out a quantitative comparison of the two methods. However, the previous study by Lauer et al. demonstrated that the dosages of ASA and CPG used in our study were sufficient to significantly reduce platelet aggregation as measured by aggregometry (14), which is in line with our current results based on FACS measurements.

In summary, we describe a versatile and easy-to-implement tool to investigate the impact of platelet function in experimenta stroke. We demonstrated that ASA+CPG treatment resulted in significantly impaired platelet function contributing to an increased risk of HT after experimental stroke and tPA administration. Our test can be used in animal studies to monitor drug effects. To identify and exclude mice with insufficient platelet inhibition from future experiments, it can be implemented at various times within the model and repeated using dynamic measurements. We here offer an experimental model to better investigate and understand the mechanisms underlying the impaired platelet function contributing to HT.

\section{DATA AVAILABILITY STATEMENT}

All datasets generated for this study are included in the article/Supplementary Material.

\section{ETHICS STATEMENT}

The animal study was reviewed and approved by Institutional Animal Care and Use Committee (IACUC) at Massachusetts General Hospital (MGH).

\section{AUTHOR CONTRIBUTIONS}

CF, KL, and FL conceived the idea, designed the model and analyzed the data. FL carried out the experiments and performed the flow cytometry measurements. YZ performed the MCAO surgery. FL processed the experimental data, performed the statistical analysis, drafted the article, and designed the figures. JS aided in interpreting the results. KL and CF supervised the work. CF and KL made critical revisions of the article for important intellectual content. All authors discussed the results and commented on the article.

\section{FUNDING}

This work was supported by the National Institutes of Health (R01NS049430 to KL); the American Heart Association (17GRNT33460100 to KL); and the Faculty of Medicine, Goethe University Frankfurt (FPF doctoral scholarship to FL).

\section{ACKNOWLEDGMENTS}

The authors thank Dr. Xiaoying Wang, Dr. Eng H. Lo, Dr. Ken Arai, and Dr. Gen Hamanaka for helpful discussions, and Kelly Kin Chung for help with the manuscript. We gratefully acknowledge the National Institutes of Health and the American Heart Association for their financial support of this work.

\section{SUPPLEMENTARY MATERIAL}

The Supplementary Material for this article can be found online at: https://www.frontiersin.org/articles/10.3389/fneur. 2020.00085/full\#supplementary-material

\section{REFERENCES}

1. Johnston SC, Easton JD, Farrant M, Barsan W, Conwit RA, Elm JJ, et al. Clopidogrel and aspirin in acute ischemic stroke and high-risk TIA. N Eng I Med (2018) 379:215-25. doi: 10.1056/NEJMoa1800410

2. Wang Y, Wang Y, Zhao X, Liu L, Wang D, Wang C, et al. Clopidogrel with aspirin in acute minor stroke or transient ischemic attack. $N$ Engl J Med. (2013) 369:11-9. doi: 10.1056/NEJMoa1215340

3. Levine GN, Bates ER, Blankenship JC, Bailey SR, Bittl JA, Cercek B, et al 2011 ACCF/AHA/SCAI guideline for percutaneous coronary intervention. Am Coll Cardiol. (2011) 58:e44-122. doi: 10.1016/j.jacc.2011.08.007

4. Brott TG, Hobson RW, Howard G, Roubin GS, Clark WM, Brooks W, et al. Stenting versus endarterectomy for treatment of carotid-artery stenosis. $N$ Engl J Med. (2010) 363:11-23. doi: 10.1056/NEJMx100035

5. Valgimigli M, Bueno H, Byrne RA, Collet JP, Costa F, Jeppsson A, et al 2017 ESC focused update on dual antiplatelet therapy in coronary artery 
disease developed in collaboration with EACTS. Eur J Cardio-thoracic Surg. (2018) 53:34-78. doi: 10.1093/eurheartj/ehx419

6. Yang Y, Zhou M, Zhong X, Wang Y, Zhao X, Liu L, et al. Dual versus mono antiplatelet therapy for acute non-cardioembolic ischaemic stroke or transient ischaemic attack : a systematic review and meta-analysis. Stroke Vasc Neurol. (2018) 3:107-16. doi: 10.1136/svn-2018-000168

7. Mazya M, Egido JA, Ford GA, Lees KR, Mikulik R, Toni D, et al. Predicting the risk of symptomatic intracerebral hemorrhage in ischemic stroke treated with intravenous alteplase: Safe Implementation of Treatments in Stroke (SITS) symptomatic intracerebral hemorrhage risk score. Stroke. (2012) 43:152431. doi: 10.1161/STROKEAHA.111.644815

8. Diedler J, Ahmed N, Sykora M, Uyttenboogaart M, Overgaard K, Luijckx GJ, et al. Safety of intravenous thrombolysis for acute ischemic stroke in patients receiving antiplatelet therapy at stroke onset. Stroke. (2010) 41:288 94. doi: 10.1161/STROKEAHA.109.559724

9. Powers WJ, Rabinstein AA, Ackerson T, Adeoye OM, Bambakidis NC Becker K, et al. 2018 guidelines for the early management of patients with acute ischemic stroke: a guideline for healthcare professionals from the American Heart Association/American Stroke Association. Stroke. (2018) 49:46-110. doi: 10.1161/STR.0000000000000163

10. The European Stroke Organisation (ESO) Executive Committee and the ESO Writing Committee. Guidelines for Management of Ischaemic Stroke and Transient Ischaemic Attack 2008. Cerebrovasc Dis. (2008) 25:457507. doi: $10.1159 / 000131083$

11. Gensicke H, Al Sultan AS, Strbian D, Hametner C, Zinkstok SM, Moulin S, et al. Intravenous thrombolysis and platelet count. Neurology. (2018) 90:e1-8. doi: 10.1212/WNL.0000000000004982

12. Zheng Y, Lieschke F, Schaefer JH, Wang X, Foerch C, van Leyen K. Dual antiplatelet therapy increases hemorrhagic transformation following thrombolytic treatment in experimental stroke. Stroke. (2019) 50:36503. doi: 10.1161/STROKEAHA.119.027359

13. Hughes $\mathrm{CE}$. How to perform aggregometry and lumi-aggregometry in mouse platelets. Platelets. (2018) 29:638-43. doi: 10.1080/09537104.2018.1478074

14. Lauer A, Schlunk F, Van Cott EM, Steinmetz H, Lo EH, Foerch C. Antiplatelet pretreatment does not increase hematoma volume in experimental intracerebral hemorrhage. J Cereb Blood Flow Metab. (2011) 31:1736-42. doi: 10.1038/jcbfm.2011.22

15. Kruse-Jarres R, Singleton TC, Leissinger CA. Identification and basic management of bleeding disorders in adults. J Am Board Fam Med. (2014) 27:549-64. doi: 10.3122/jabfm.2014.04.130227

16. Peterson P, Hayes TE, Arkin CF, Bovill EG, Fairweather RB, Rock William AJ, et al. The preoperative bleeding time test lacks clinical benefit: college of American Pathologists' and American Society of Clinical Pathologists' position article. JAMA Surg. (1998) 133:134-9. doi: 10.1001/archsurg.133.2.134

17. Armstrong PCJ, Kirkby NS, Chan MV, Finsterbusch M, Hogg N, Nourshargh $S$, et al. Novel whole blood assay for phenotyping platelet reactivity in mice identifies ICAM-1 as a mediator of platelet-monocyte interaction. Blood (2015) 126:e11-8. doi: 10.1182/blood-2015-01-621656

18. De Cuyper IM, Meinders M, Van De Vijver E, De Korte D, Porcelijn L, De Haas $\mathrm{M}$, et al. A novel $\mathrm{fl}$ ow cytometry - based platelet aggregation assay. Blood. (2013) 121:70-80. doi: 10.1182/blood-2012-06-437723

19. Kassassir H, Siewiera K, Sychowski R, Watała C. Can the antiplatelet effects of cangrelor be reliably studied in mice under in vivo and in vitro conditions using flow cytometry? Pharmacol Rep. (2013) 65:87083. doi: 10.1016/S1734-1140(13)71068-5

20. Liu Y, L JN, M DA, Du X-J. Standardizing a simpler, more sensitive and accurate tail bleeding assay in mice. World J Exp Med. (2012) 2:30. doi: 10.5493 /wjem.v2.i2.30

21. Momi S, Pitchford SC, Alberti PF, Minuz P, Del Soldato P, Gresele P. Nitroaspirin plus clopidogrel versus aspirin plus clopidogrel against platelet thromboembolism and intimal thickening in mice. Thromb Haemost. (2005) 93:535-43. doi: 10.1160/TH04-07-0464

22. Tsakiris DA, Scudder L, Hodivala-Dilke K, Hynes RO, Coller BS. Hemostasis in the mouse (Mus musculus): a review. Thrombosis Haemostasis. (1999) 81:177-88. doi: 10.1055/s-0037-1614439

23. Saito MS, Lourenço AL, Kang HC, Rodrigues CR, Cabral LM, Castro HC, et al. New approaches in tail-bleeding assay in mice: improving an important method for designing new anti-thrombotic agents. Int J Exp Pathol. (2016) 97:285-92. doi: 10.1111/iep.12182

24. Von Kummer R, Broderick JP, Campbell BCV, Demchuk A, Goyal M, Hill $\mathrm{MD}$, et al. The heidelberg bleeding classification: Classification of bleeding events after ischemic stroke and reperfusion therapy. Stroke. (2015) 46:29816. doi: 10.1161/STROKEAHA.115.010049

25. Yaghi S, Willey JZ, Cucchiara B, Goldstein JN, Gonzales NR, Khatri P, et al. Treatment and outcome of hemorrhagic transformation after intravenous alteplase in acute ischemic stroke: a scientific statement for healthcare professionals from the American Heart Association/American Stroke Association. Stroke. (2017) 48:e343-61. doi: 10.1161/STR.0000000000000152

26. García-Yébenes I, Sobrado M, Zarruk JG, Castellanos M, De La Ossa NP, Dávalos A, et al. A mouse model of hemorrhagic transformation by delayed tissue plasminogen activator administration after in situ thromboembolic stroke. Stroke. (2011) 42:196-203. doi: 10.1161/STROKEAHA.110.600452

27. Copin J-C, Gasche Y. Effect of the duration of middle cerebral artery occlusion on the risk of hemorrhagic transformation after tissue plasminogen activator injection in rats. Brain Res. (2008) 1243:161-6. doi: 10.1016/j.brainres.2008.09.025

28. Van Velzen JF, Laros-Van Gorkom BAP, Pop GAM, Van Heerde WL. Multicolor flow cytometry for evaluation of platelet surface antigens and activation markers. Thromb Res. (2012) 130:92-8. doi: 10.1016/j.thromres.2012.02.041

29. Li Y, Landqvist C, Grimm SW. Disposition and metabolism of ticagrelor, a novel $\mathrm{P}_{2} \mathrm{Y}_{12}$ receptor antagonist, in mice, rats, and marmosets. Drug Metab Dispos. (2011) 39:1555-67. doi: 10.1124/dmd.111.039669

30. Wientjes MG, Levy G. Nonlinear pharmacokinetics of aspirin in rats. $J$ Pharmacol Exp Ther. (1988) 245:809-15.

31. Cucchiara B, Tanne D, Levine SR, Demchuk AM, Kasner S. A Risk score to predict intracranial hemorrhage after recombinant tissue plasminogen activator for acute ischemic stroke. J Stroke Cerebrovasc Dis. (2008) 17:3313. doi: 10.1016/j.jstrokecerebrovasdis.2008.03.012

32. Lou M, Safdar A, Mehdiratta M, Kumar S, Schlaug G, Caplan L, et al. The HAT score. Neurology. (2008) 71:141723. doi: 10.1212/01.wnl.0000330297.58334.dd

33. Strbian D, Engelter S, Michel P, Meretoja A, Sekoranja L, Ahlhelm FJ, et al. Symptomatic intracranial hemorrhage after stroke thrombolysis: the SEDAN Score. Ann Neurol. (2012) 71:634-41. doi: 10.1002/ana.23546

34. Saver JL. Hemorrhage after thrombolytic therapy for stroke: the clinically relevant number needed to harm. Stroke. (2007) 38:2279-83, doi: 10.1161/STROKEAHA. 107.487009

35. Menon BK, Saver JL, Prabhakaran S, Reeves M, Liang L, Olson DM, et al. Risk score for intracranial hemorrhage in patients with acute ischemic stroke treated with intravenous tissue-type plasminogen activator. Stroke. (2012) 43:2293-9. doi: 10.1161/STROKEAHA.112.660415

36. Whiteley WN, Bruins SK, Peter F, Peter S, Joanna W. Risk Factor for intracranial hemorrhage in acute ischemic stroke patients treated with recombinant tissue plasminogen activator. Stroke. (2012) 43:29049. doi: 10.1161/STROKEAHA.112.665331

37. Luo S, Zhuang M, Zeng W, Tao J. Intravenous thrombolysis for acute ischemic stroke in patients receiving antiplatelet therapy: a systematic review and meta-analysis of 19 studies. J Am Heart Assoc. (2016) 5:114. doi: 10.1161/JAHA.116.003242

38. Xian Y, Federspiel JJ, Grau-Sepulveda M, Hernandez AF, Schwamm LH, Bhatt DL, et al. Risks and benefits associated with prestroke antiplatelet therapy among patients with acute ischemic stroke treated with intravenous tissue plasminogen activator. JAMA Neurol. (2016) 73:509. doi: 10.1001/jamaneurol.2015.3106

39. Tsivgoulis G, Katsanos AH, Mavridis D, Gdovinova Z, Karlinski M, Macleod MJ, et al. Intravenous thrombolysis for ischemic stroke patients on dual antiplatelets. Ann Neurol. (2018) 84:89-97. doi: 10.1002/ana.25269

40. Chen F, Maridakis V, O’Neill EA, Beals C, Radziszewski W, De Lepeleire I et al. A randomized clinical trial comparing point-of-care platelet function assays and bleeding time in healthy subjects treated with aspirin or clopidogrel. Platelets. (2012) 23:249-58. doi: 10.3109/09537104.2011.604806

41. Breuer L, Huttner HB, Kiphuth IC, Ringwald J, Hilz MJ, Schwab S, et al. Waiting for platelet counts causes unsubstantiated delay of thrombolysis therapy. Eur Neurol. (2013) 69:317-20. doi: 10.1159/000345702 
42. Ramström S, Södergren A, Tynngård N, Lindahl T, Lindahl TL. Platelet function determined by flow cytometry: new perspectives? platelet function determined by flow cytometry -new perspectives? Semin Thromb Hemost. (2016) 3:268-81. doi: 10.1055/s-0035-1570082

43. Gremmel T, Koppensteiner R, Panzer S. Comparison of aggregometry with flow cytometry for the assessment of agonists'-induced platelet reactivity in patients on dual antiplatelet therapy. PLoS ONE. (2015) 10:e0129666. doi: 10.1371/journal.pone.0129666

44. Vinholt PJ. The role of platelets in bleeding in patients with thrombocytopenia and hematological disease. Clin Chem Lab Med. (2019) 57:1808. doi: 10.1515/cclm-2019-0380

45. Krishnegowda M, Rajashekaraiah V. Platelet disorders: an overview. Blood Coagul Fibrinolysis. (2015) 26:479-91. doi: $10.1097 / 01 . \mathrm{mbc} .0000469521 .23628 .2 \mathrm{~d}$

46. Panzer S, Rieger $M$, Vormittag R, Eichelberger B, Dunkler $D$, Pabinger I. Platelet function to estimate the bleeding risk in autoimmune thrombocytopenia. Eur J Clin Invest. (2007) 37:814-9. doi: $10.1111 / \mathrm{j} .1365-2362.2007 .01855 \mathrm{x}$
47. Frelinger AL, Grace RF, Gerrits AJ, Berny-Lang MA, Brown T, Carmichael SL, et al. Platelet function tests, independent of platelet count, are associated with bleeding severity in ITP. Blood. (2015) 126:873-9. doi: 10.1182/blood-2015-02-6 28461

Conflict of Interest: The authors declare that the research was conducted in the absence of any commercial or financial relationships that could be construed as a potential conflict of interest.

Copyright (c) 2020 Lieschke, Zheng, Schaefer, van Leyen and Foerch. This is an open-access article distributed under the terms of the Creative Commons Attribution License (CC BY). The use, distribution or reproduction in other forums is permitted, provided the original author(s) and the copyright owner(s) are credited and that the original publication in this journal is cited, in accordance with accepted academic practice. No use, distribution or reproduction is permitted which does not comply with these terms. 


\section{frontiers}

\section{Supplementary Material}

\section{$1 \quad$ Supplementary Data}

\subsection{Sample size calculation}

Power calculations were based on the normalized hemorrhage observed in a preliminary study comparing MCAO and tPA-treated mice with or without ASA+CPG pretreatment (Supplemental Figure 1). Using a power of 0.8 and a significance level of 0.05 , an approximate sample size required of 6 animals per group was calculated. Anticipating a larger variability of HT within ASA+CPG pretreated animals (not every pretreated mouse consequently developed HT) and to compensate for dead or excluded animals, we randomized a larger number of mice per group. This preliminary study was also used for our recent mouse study on ASA + CPG in ischemic stroke ${ }^{1}$.

\subsection{Overall HT Types}

Hemorrhages were classified according to the ECASS II morphologic definitions ${ }^{2,3}$ adapted to animal models as used in previous publications ${ }^{1,4,5}$. Therefore, every section was individually scored on a 5 point ordinal scale (class $1=$ no HT; $2=$ hemorrhagic infarction type $1 ; 3=$ hemorrhagic infarction type 2; 4=parenchymal hemorrhage type 1;5=parenchymal hemorrhage type 2) and an overall grade for every brain was determined according to the highest grade occurring among the sections. The results are shown in the supplementary table I.

\section{Supplementary Figures and Tables}

\subsection{Supplementary Figure 1}

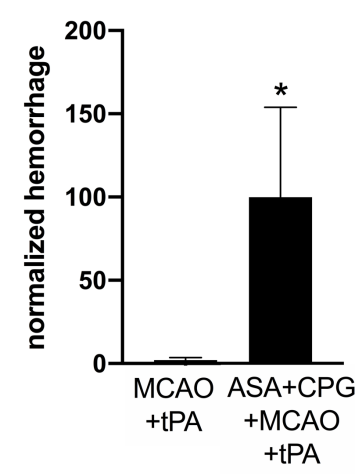

Supplemental Figure 1. Preliminary experiment on ASA $+\mathrm{CPG}$ mice vs. control mice. Control mice total hemorrhage (combined brain surface and sections measurements) was only $2.2 \pm 1.4 \%$ of the total hemorrhage determined in ASA+CPG mice. 
2.2 Supplementary Table I

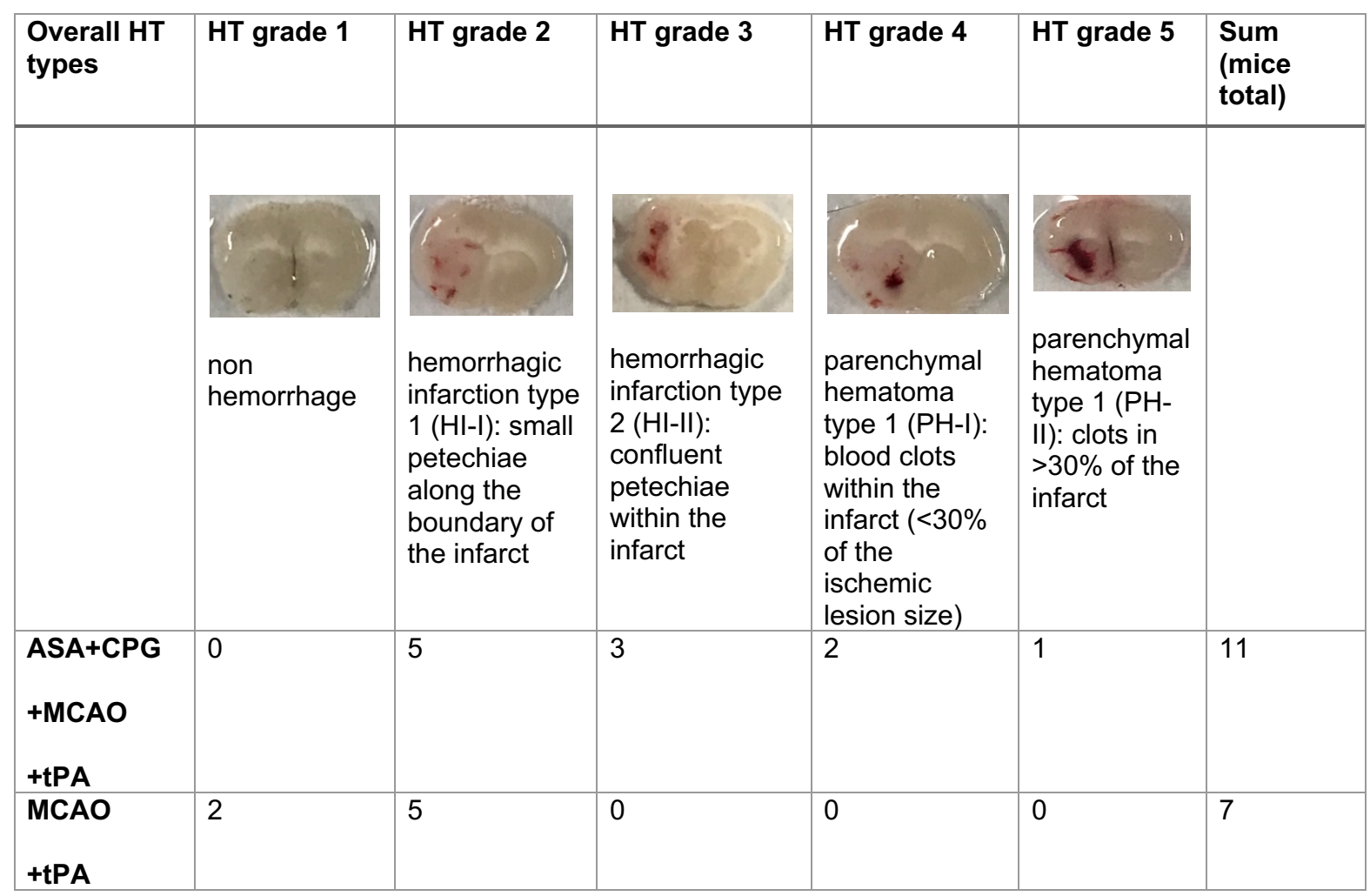

Supplementary Table I. Morphological classification of the bleeding types. $\mathrm{MCAO}=$ transient middle cerebral artery occlusion; $\mathrm{ASA}+\mathrm{CPG}=\mathrm{Aspirin}$ and Clopidogrel; $\mathrm{HT}=$ Hemorrhagic

Transformation; $\mathrm{HI}=$ Hemorrhagic infarction; $\mathrm{PH}=$ Parenchymal hematoma; $\mathrm{PA}=$ tissue plasminogen activator. 


\subsection{Supplementary Table II}

\begin{tabular}{|c|c|c|c|c|}
\hline Experimental group & $\begin{array}{l}\text { Included } \\
\text { samples }\end{array}$ & $\begin{array}{l}\text { Excluded } \\
\text { samples (platelet } \\
\text { count less than } \\
1000 \text { events-due } \\
\text { to poor blood } \\
\text { collection) }\end{array}$ & $\begin{array}{l}\text { Excluded due to } \\
\text { processing error } \\
\text { (failed labelling) }\end{array}$ & $\begin{array}{l}\text { Total blood } \\
\text { samples }\end{array}$ \\
\hline Control & 12 & 0 & 0 & 12 \\
\hline $\mathbf{A S A}+\mathbf{C P G}$ & 15 & 0 & 1 & 16 \\
\hline
\end{tabular}

Supplementary Table II. Inclusion and exclusion criteria pre-stroke flow cytometry based platelet function testing.

\subsection{Supplementary Table III}

\begin{tabular}{|l|l|l|l|l|}
\hline Experimental group & Included mice & $\begin{array}{l}\text { Excluded mice- } \\
\text { died during } \\
\text { observation } \\
\text { period }\end{array}$ & $\begin{array}{l}\text { Excluded mice- } \\
\text { poor physical } \\
\text { condition (low } \\
\text { body temp, slowly } \\
\text { breathing) }\end{array}$ & Total mice \\
\hline MCAO+tPA & 4 & 4 & 4 & 12 \\
\hline ASA+CPG+MCAO+tPA & 8 & 2 & 6 & 16 \\
\hline
\end{tabular}

Supplementary Table III. Inclusion and exclusion criteria tail bleeding.

\subsection{Supplementary Table IV}

\begin{tabular}{|l|l|l|l|l|l|}
\hline Experimental group & $\begin{array}{l}\text { Included } \\
\text { mice }\end{array}$ & $\begin{array}{l}\text { Excluded mice- } \\
\text { died during } \\
\text { observation } \\
\text { period }\end{array}$ & $\begin{array}{l}\text { Excluded mice- } \\
\text { mean tail } \\
\text { bleeding } \\
\text { volume } \pm \text { >2*SD }\end{array}$ & $\begin{array}{l}\text { Excluded } \\
\text { mice due to } \\
\text { surgical } \\
\text { error during } \\
\text { MCAO } \\
\text { surgery }\end{array}$ & $\begin{array}{l}\text { Total } \\
\text { mice }\end{array}$ \\
\hline MCAO+tPA & 7 & 4 & 1 & 0 & 12 \\
\hline ASA+CPG+MCAO+tPA & 11 & 2 & 1 & 2 & 16 \\
\hline
\end{tabular}

Supplementary Table IV. Inclusion and exclusion criteria HT quantification. 
Supplementary Material

\section{Supplementary Literature}

1. Zheng Y, Lieschke F, Schaefer JH, Wang X, Foerch C, van Leyen K. Dual Antiplatelet Therapy Increases Hemorrhagic Transformation Following Thrombolytic Treatment in Experimental Stroke. Stroke. 2019;0(0):STROKEAHA.119.027359.

doi:10.1161/STROKEAHA.119.027359

2. Von Kummer R, Broderick JP, Campbell BCV, et al. The heidelberg bleeding classification: Classification of bleeding events after ischemic stroke and reperfusion therapy. Stroke. 2015;46(10):2981-2986. doi:10.1161/STROKEAHA.115.010049

3. Yaghi S, Willey JZ, Cucchiara B, et al. Treatment and Outcome of Hemorrhagic Transformation After Intravenous Alteplase in Acute Ischemic Stroke: A Scientific Statement for Healthcare Professionals From the American Heart Association/American Stroke Association. Stroke. 2017;48(12):e343-e361. doi:10.1161/STR.0000000000000152

4. García-Yébenes I, Sobrado M, Zarruk JG, et al. A mouse model of hemorrhagic transformation by delayed tissue plasminogen activator administration after in situ thromboembolic stroke. Stroke. 2011;42(1):196-203. doi:10.1161/STROKEAHA.110.600452

5. Copin J-C, Gasche Y. Effect of the duration of middle cerebral artery occlusion on the risk of hemorrhagic transformation after tissue plasminogen activator injection in rats. Brain Res. 2008;1243:161-166. doi:https://doi.org/10.1016/j.brainres.2008.09.025 
8 Manuskript "Dual Antiplatelet Therapy Increases Hemorrhagic Transformation Following Thrombolytic Treatment in Experimental Stroke" 


\title{
Brief Report
}

\section{Dual Antiplatelet Therapy Increases Hemorrhagic Transformation Following Thrombolytic Treatment in Experimental Stroke}

\author{
Yi Zheng, PhD*; Franziska Lieschke*; Jan Hendrik Schaefer, MD; Xiaoying Wang, MD, PhD;
} Christian Foerch, MD; Klaus van Leyen, $\mathrm{PhD}$

Background and Purpose - Dual antiplatelet treatment poses a risk for increased hemorrhagic transformation (HT) following intravenous thrombolysis and mechanical thrombectomy. The aim of this study was to implement a model of experimental stroke with tissue-type plasminogen activator (tPA)-associated HT in mice on dual antiplatelet treatment to enable mechanistic studies and also to allow for an initial assessment of therapeutic approaches to limit HT.

Methods-Male C57BL6 mice were fed with Aspirin and Clopidogrel via drinking water for 3 days. Subsequently, mice were subjected to 2-hour transient middle cerebral artery occlusion, and tPA was infused when indicated. HT was quantified by measuring hemorrhaged areas in brain sections with ImageJ. TTC staining was used to determine infarct size. Platelet function was tested in vitro using flow cytometry and in vivo with standard tail bleeding tests.

Results - Both flow cytometry and tail bleeding volumes indicated significantly reduced platelet function following Aspirin and Clopidogrel treatment. While tPA administered 2 hours after onset of middle cerebral artery occlusion did not cause bleeding in control mice $(0.51 \pm 0.13 \mathrm{~mm} 2)$, HT significantly increased by $18.9 \pm 5.4 \mathrm{~mm} 2(P=0.0045)$ in Aspirin and Clopidogrel mice treated with tPA. HT in aspirin and clopidogrel mice not treated with tPA was nonsignificantly elevated by $8.0 \pm 4.6 \mathrm{~mm}^{2}(P=0.3784)$ compared with controls. Infarct sizes did not differ between groups. The HT persisted when the tPA dosage was reduced.

Conclusions-We successfully established a translational stroke model of tPA treatment under dual antiplatelet treatment. The impaired platelet function led to an increased risk for HT in tPA-treated mice. Reducing the dosage of tPA did not prevent this hemorrhagic complication.

Visual Overview - An online visual overview is available for this article. (Stroke. 2019;50:00-00. DOI: 10.1161/ STROKEAHA.119.027359.)

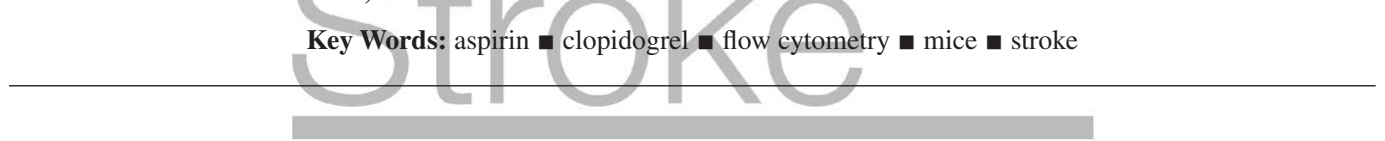

$\mathrm{D}$ ual antiplatelet therapy (DAPT) is used to prevent artherothrombotic events in high risk patients following acute coronary syndrome with or without percutaneous coronary intervention and for secondary prevention following ischemic strokes. ${ }^{1,2}$ It is estimated that patients receiving antiplatelet therapy constitute up to $40 \%$ of stroke patients. ${ }^{3}$ This leads to an increased intracranial bleeding risk when patients are subsequently treated with tPA thrombolysis with or without mechanical thrombectomy. ${ }^{4}$ Thus, developing strategies to reduce hemorrhagic complications in stroke patients on DAPT who receive tPA are of utmost importance. Animal models can be of value here, providing an experimental tool to study mechanisms of HT, and to evaluate strategies to reduce HT. It is with this purpose that we aimed to establish a mouse model of DAPT followed by experimental stroke and tPA thrombolysis. In our first test of this new model of HT, we then focused on an initial assessment of one such strategy, applying a reduced dose of tPA.

\section{Methods}

Data available on request from the authors.

Male C57/BL6 mice were fed with Aspirin and Clopidogrel (ASA+CPG) via drinking water for 72 hours and subjected to 2-hour transient middle cerebral artery occlusion. Where indicated, tPA was infused (Figure 1A). Neurological outcome, hemorrhages, and infarct size were assessed 24 hours after ischemia. HT was quantified by measuring the total hemorrhaged area in brain sections. Hemorrhages were classified according to ECASS II morphological definitions. For inclusion/exclusion criteria, see Table I in the online-only Data

Received July 1, 2019; final revision received August 13, 2019; accepted August 23, 2019.
From the Neuroprotection Research Laboratory, Department of Radiology, Massachusetts General Hospital, Harvard Medical School, Charlestown (Y.Z., F.L., X.W., K.v.L.); and Department of Neurology, University Hospital Frankfurt, Goethe-University, Frankfurt am Main, Germany (F.L., J.H.S., C.F.). *Dr Zheng and Franziska Lieschke contributed equally.

Presented in part at the International Stroke Conference, Honolulu, HI, February 6-8, 2019

The online-only Data Supplement is available with this article at https://www.ahajournals.org/doi/suppl/10.1161/STROKEAHA.119.027359.

Correspondence to Klaus van Leyen, PhD, Neuroprotection Research Laboratories, Department of Radiology, Massachusetts General Hospital, 149 13th

St, R. 2401, Charlestown, MA 02129. Email klaus_vanleyen@hms.harvard.edu

(C) 2019 American Heart Association, Inc.

Stroke is available at https://www.ahajournals.org/journal/str

DOI: 10.1161/STROKEAHA.119.027359 


\section{A}

Study part one 'ASA+CPG in experimental stroke'

\begin{tabular}{|c|c|c|c|}
\hline Control \\
\hline Control
\end{tabular}$\Rightarrow$ MCAO

Study part two 'low dose tPA in ASA+CPG stroke model'

\begin{tabular}{|c|c|c|c|c|c|c|}
\hline Control & $\Rightarrow$ & MCAO & $\Rightarrow$ & low dose tPA & $\Rightarrow$ & sacrifice \\
\hline$A S A+C P G$ & ㄷ) & MCAO & C) & low dose tPA & $\Rightarrow$ & sacrifice \\
\hline
\end{tabular}

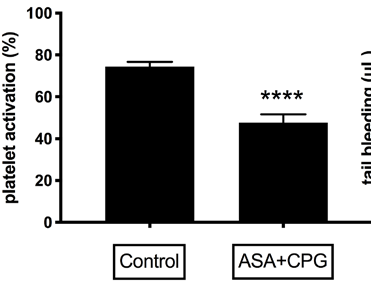

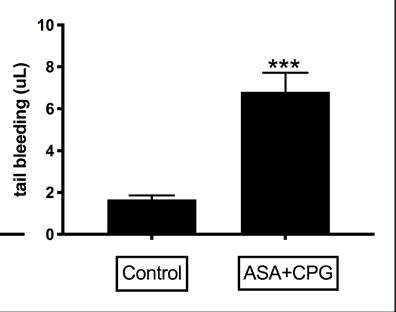

Figure 1. A, Timeline diagram. B, Platelet activation after in vitro thrombin stimulation in control and aspirin and clopidogrel (ASA+CPG) mice; $P \leq 0.0001$. C, Tail bleeding volumes in control and ASA+CPG mice; $P=0.0002$. MCAO indicates middle cerebral artery occlusion; and tPA, tissue-type plasminogen activator.

Supplement. Platelet function was tested in vitro using flow cytometry and in vivo with standard tail bleeding tests. For details see Methods in the online-only Data Supplement.

\section{Results}

Platelet function was significantly impaired following 3 days of ASA+CPG treatment, demonstrated ex vivo using flow cytometry and in vivo with standard tail bleeding tests (Figure 1B and 1C). To evaluate the effect of DAPT on hemorrhage, we subjected mice to 2 hours of middle cerebral artery occlusion followed by 22 hours of reperfusion in 4 groups. As expected, control mice not pretreated with ASA+CPG, and mice treated with tPA at the early time point of 2 hours after onset of ischemia showed very little hemorrhage $(0.51 \pm 0.13$ and $0.55 \pm 0.29 \mathrm{~mm} 2$, respectively; Figure $2 \mathrm{~A})$.
Mice receiving ASA+CPG but no tPA showed some hemorrhage, but the increase compared with control mice was not significant $(8.49 \pm 4.45 \mathrm{~mm} 2 ; P=0.3784)$. In contrast, mice receiving both $\mathrm{ASA}+\mathrm{CPG}$ pretreatment and tPA showed significantly increased hemorrhage compared with control mice $(19.04 \pm 5.96 \mathrm{~mm} 2 ; P=0.0045)$. These findings were confirmed by morphological classification of the bleeding types, where $5 / 7$ mice receiving both $\mathrm{ASA}+\mathrm{CPG}$ pretreatment and $\mathrm{PA}$ were rated $\mathrm{HI}-2$ and higher, compared with $0 / 10$ in the middle cerebral artery occlusion group $(P=0.0043$; see Table II the onlineonly Data Supplement). TTC staining showed no significant difference in the infarct sizes between groups, suggesting lesion size was not a determining factor for the amount of HT (Figure 2B). HT typically occurred along the boundary of the infarct or within the infarct core. No hemorrhages were found

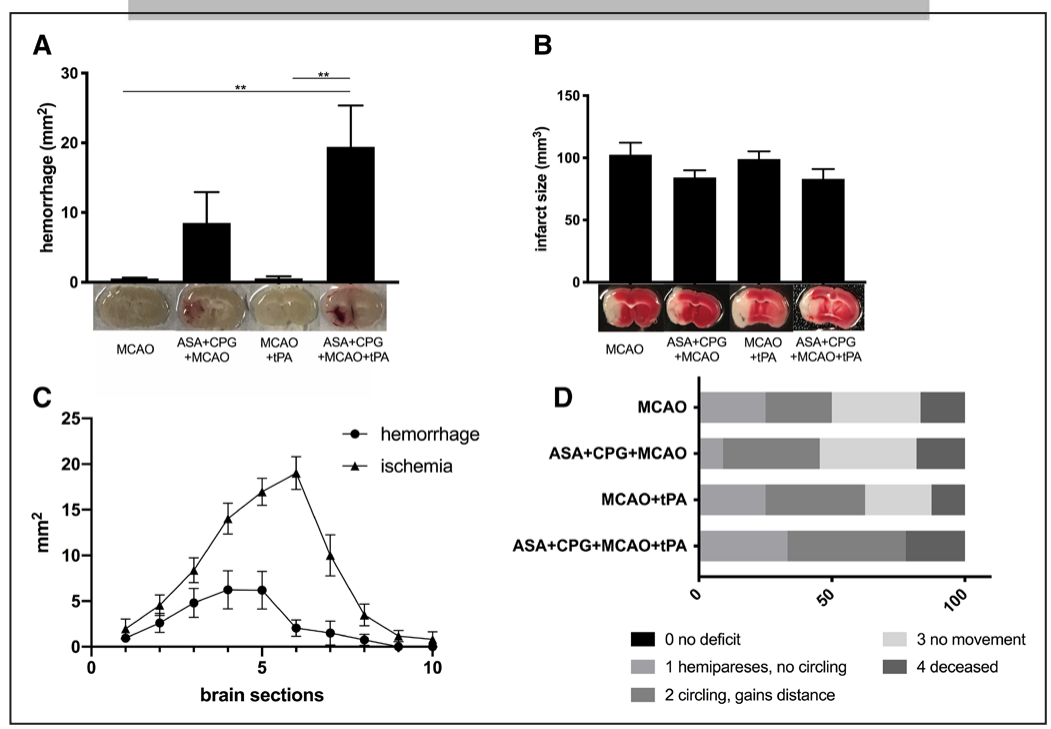

Figure 2. A, Hemorrhagic transformation in brain sections $24 \mathrm{~h}$ after middle cerebral artery occlusion (MCAO). B, Infarct sizes. C, Hemorrhage-to-infarctprofile of aspirin and clopidogrel (ASA+CPG) mice, $24 \mathrm{~h}$ after $2 \mathrm{~h} \mathrm{MCAO+tissue-type} \mathrm{plasminogen} \mathrm{activator} \mathrm{(tPA)} \mathrm{treatment.} \mathrm{D,} \mathrm{Neurological} \mathrm{outcome} \mathrm{(in} \mathrm{\%} \mathrm{of}$ animals per group, $P=0.6351$ ). 

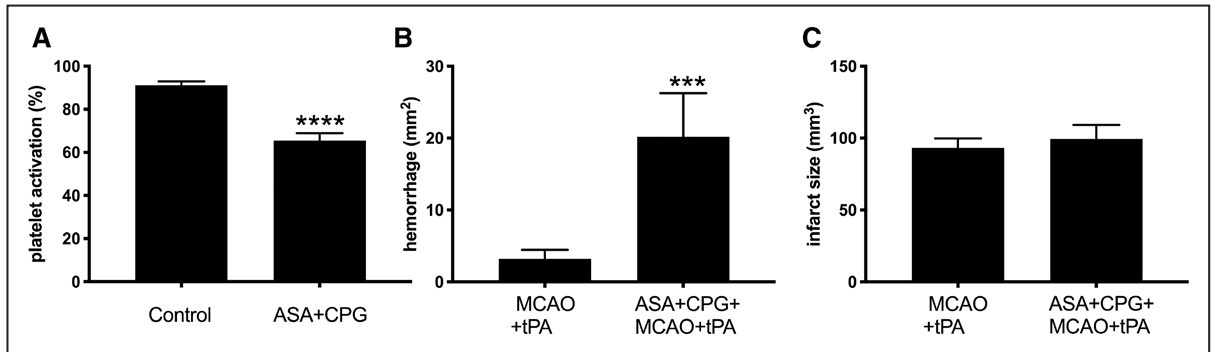

Figure 3. Low-dose tissue-type plasminogen activator (tPA) in Aspirin and Clopidogrel (ASA+CPG) model. A, Platelet activation upon in vitro thrombin stimulation $(P<0.0001)$. B, HT in brain sections $24 \mathrm{~h}$ after 2-h middle cerebral artery occlusion (MCAO) and low-dose tPA treatment. C, Infarct sizes.

remote from the infarct, for example, in the contralateral hemisphere (Figure 2C). Neurological outcome and mortality were not significantly different $(P=0.6351$ and $P=0.9625$, respectively; Figure 2D).

\section{Low-Dose tPA in ASA+CPG Stroke Model}

In vitro platelet activation was significantly decreased by $25.67 \pm 3.64 \%$ in ASA+CPG mice compared with controls (Figure 3A; $P<0.0001$ ). Low-dose tPA in ASA+CPG mice still significantly increased HT by $19.3 \pm 5.436 \mathrm{~mm}^{2}$ (Figure 3B; $P=0.0010)$ compared with controls receiving low-dose tPA. Infarct size (Figure 3C; $P=0.7386$ ), neurological outcome $(P=0.4942)$, and mortality $(P=0.9638)$ did not differ significantly.

\section{Discussion}

We have established an experimental stroke model of tPA treatment under DAPT. Our findings document increased levels of HT in mice treated with both DAPT and IPA, which persist when low-dose tPA is used.

Our group recently investigated the effects of warfarin pretreatment on HT following stroke with and without tPA treatment. Warfarin led to severe bleeding complications, which could be ameliorated using either an anticoagulant reversal agent $^{5}$ or an inhibitor of a downstream effector, 12/15-lipoxygenase, ${ }^{6}$ demonstrating the feasibility of translational studies of HT. In contrast, the effects of DAPT have not been investigated before in models of ischemic stroke.

To improve the safety profile of IPA in patients with preexisting risk factors, the use of low-dose tPA was previously studied. ${ }^{7-9}$ A prespecified subgroup analysis of patients on prestroke DAPT in the ENCHANTED trial (Enhanced Control of Hypertension and Thrombolysis Stroke Study) identified a borderline significant interaction $(P=0.052)$ for a better functional outcome when using low-dose tPA. ${ }^{10}$ Adapting this approach to the mouse model, the administration of low-dose tPA still significantly increased $\mathrm{HT}$ in ASA+CPG treated mice compared with controls. The level of HT was similar to that previously found for standard dose tPA, suggesting that the dosage reduction does not provide a benefit in this model.

There are several limitations to our study. (1) The risk of tPA associated HT in our experimental model may differ from that in human patients, who often suffer from comorbidities and additional risk factors. (2) The selected dosages for ASA, CPG, and tPA were significantly higher than those used in humans because of the increased drug metabolic rate in mice. The dosages chosen were based on previous studies and published literature, and ASA+CPG treatment effects were monitored carefully in each mouse. (3) We used the filament model of MCA occlusion which models mechanical thrombectomy. ${ }^{11}$ This is useful to evaluate HT in the context of combining tPA treatment with endovascular therapy—currently addressed in the SWIFT DIRECT trial—but may miss potentially aggravating thrombus-endothelial cell interactions. Finally, we used exclusively male animals in this pilot study to limit variability because of sex differences.

The model we have established here can now be used to test novel forms of intervercention geared toward reducing HT following tPA thrombolysis in patients on DAPT. This includes strategies like replacing CPG with the newer ADP receptor antagonist ticagrelor, as well as adding treatments to inhibit hemorrhage-inducing pathways. Ultimately, these studies may lead to a safer use of tPA in the context of preexisting antiplatelet treatment, promoting the use of tPA in a larger patient population than is currently reached.

\section{Acknowledgments}

We thank Dr Eng H. Lo for helpful discussions. We gratefully acknowledge the National Institutes of Health and the American Heart Association for their financial support of this work.

\section{Sources of Funding}

This study was supported by NIH/NINDS (R01NS049430 to Dr van Leyen) and American Heart Association (17GRNT33460100 to Dr van Leyen), Faculty of medicine, Goethe University Frankfurt (FPF doctoral scholarship to F. Lieschke).

\section{Disclosures}

Dr Foerch reports personal fees from Boehringer Ingelheim, grants from Sanofi Genzyme, personal fees from Merck, personal fees from Bristol Myers Squibb, personal fees from Teva, personal fees from Biogen, personal fees from Prediction Bioscience, and personal fees from Roche outside the submitted work; in addition, Dr Foerch has a patent to GFAP (glial fibrillary acidic protein) for identification of intracerebral hemorrhage issued. Dr Schaefer reports nonfinancial support from Biogen and nonfinancial support from Boehringer outside the submitted work.

\section{References}

1. Johnston SC, Easton JD, Farrant M, Barsan W, Conwit RA, Elm JJ, et al; Clinical Research Collaboration, Neurological Emergencies Treatment Trials Network, and the POINT Investigators. Clopidogrel and aspirin in 


\section{$4 \quad$ Stroke December 2019}

acute ischemic stroke and high-risk TIA. N Engl J Med. 2018;379:215225. doi: $10.1056 /$ NEJMoa1 800410

2. Wang Y, Wang Y, Zhao X, Liu L, Wang D, Wang C, et al; CHANCE Investigators. Clopidogrel with aspirin in acute minor stroke or transient ischemic attack. NEngl JMed. 2013;369:11-19. doi: 10.1056/NEJMoa1215340

3. Wahlgren N, Ahmed N, Dávalos A, Ford GA, Grond M, Hacke W, et al; SITS-MOST Investigators. Thrombolysis with alteplase for acute ischaemic stroke in the safe implementation of thrombolysis in StrokeMonitoring Study (SITS-MOST): an observational study. Lancet. 2007;369:275-282. doi: 10.1016/S0140-6736(07)60149-4

4. Pan X, Zhu Y, Zheng D, Liu Y, Yu F, Yang J. Prior antiplatelet agent use and outcomes after intravenous thrombolysis with recombinant tissue plasminogen activator in acute ischemic stroke: a meta-analysis of cohort studies and randomized controlled trials. Int J Stroke. 2015;10:317-323. doi: $10.1111 /$ ijs. 12431

5. Pfeilschifter W, Spitzer D, Pfeilschifter J, Steinmetz H, Foerch C. Warfarin anticoagulation exacerbates the risk of hemorrhagic transformation after rt-PA treatment in experimental stroke: therapeutic potential of PCC. PLoS One. 2011;6:e26087. doi: 10.1371/journal.pone.0026087

6. Liu Y, Zheng Y, Karatas H, Wang X, Foerch C, Lo EH, et al. 12/15-Lipoxygenase inhibition or knockout reduces warfarin-associated hemorrhagic transformation after experimental stroke. Stroke. 2017;48:445-451. doi: 10.1161/STROKEAHA.116.014790
7. Uchino K, Alexandrov AV, Garami Z, El-Mitwalli A, Morgenstern LB, Grotta JC. Safety and feasibility of a lower dose intravenous TPA therapy for ischemic stroke beyond the first three hours. Cerebrovasc Dis. 2005;19:260-266. doi: 10.1159/000084090

8. Deguchi I, Tanahashi N, Takao M. Clinical Study of Intravenous, low-dose recombinant tissue plasminogen activator for acute cerebral infarction: comparison of treatment within 3 hours versus 3-4.5 hours. J Stroke Cerebrovasc Dis. 2018;27:1033-1040. doi: 10.1016/j.jstrokecerebrovasdis.2017.11.009

9. Liu H, Zheng H, Cao Y, Pan Y, Wang D, Zhang R, et al. Low- versus standard-dose intravenous tissue-type plasminogen activator for acute ischemic stroke: an updated meta-analysis. J Stroke Cerebrovasc Dis. 2018;27:988-997. doi: 10.1016/j.jstrokecerebrovasdis.2017.11.005

10. Robinson TG, Wang X, Arima H, Bath PM, Billot L, Broderick JP, et al; ENCHANTED Investigators. Low- versus standard-dose alteplase in patients on prior antiplatelet therapy: the ENCHANTED trial (Enhanced Control of Hypertension and Thrombolysis Stroke Study). Stroke. 2017;48:1877-1883. doi: 10.1161/STROKEAHA.116.016274

11. Sutherland BA, Neuhaus AA, Couch Y, Balami JS, DeLuca GC, Hadley $\mathrm{G}$, et al. The transient intraluminal filament middle cerebral artery occlusion model as a model of endovascular thrombectomy in stroke. J Cereb Blood Flow Metab. 2016;36:363-369. doi: $10.1177 / 0271678 \times 15606722$

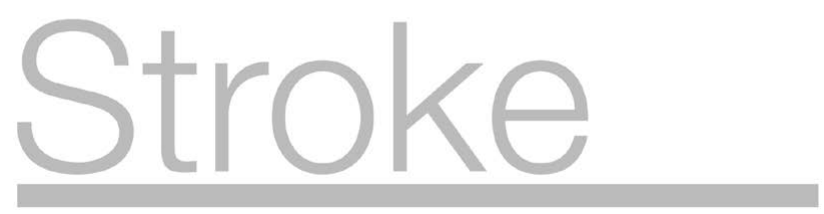


SUPPLEMENTAL MATERIAL 


\section{Supplemental Methods}

Animals

All experiments conformed to a Massachusetts General Hospital approved protocol in accordance with the National Institute of Health's guide for the care and use of laboratory animals. Male C57/BL6 mice (Jackson Laboratories, Bar Harbor, ME, USA) aged around 9 weeks with a mean body weight of 24-28 g were used. Animals were housed in ventilated cages supplied with clean water and food, with a 7 am to $7 \mathrm{pm}$ daylight cycle. Chemicals were purchased from Sigma (St. Louis, MO, USA) or Fisher Scientific (Waltham, MA, USA).

Study design and pre-planning

The first part of our study consisted of a series to assess the feasibility of our mouse model and to compare the frequency and characteristics of occurring HT. 42 mice were randomly allocated to 4 groups. All animals were subjected to $2 \mathrm{hrs} \mathrm{MCAO.} \mathrm{Group} 1$ served as controls, group 2 received pre-stroke $\mathrm{ASA}+\mathrm{CPG}$, group 3 post-stroke tPA and group 4 received both ASA + CPG pretreatment and post-stroke tPA. In the second part of our study, we assessed the use of low dose tPA for the possibility of an improved safety profile. Control and ASA $+\mathrm{CPG}$ pretreated mice were subjected to $2 \mathrm{~h} \mathrm{MCAO}$, followed by tPA treatment at $2 / 3$ of the standard dose analogous to low-dose tPA in humans ${ }^{1}$ (Figure 1A).

Sample size calculation

Power calculations were based on the normalized hemorrhage observed in a preliminary study comparing MCAO and tPA-treated mice with or without ASA $+\mathrm{CPG}$ pretreatment (Supplemental Figure I). Using a power of 0.8 and a significance level of 0.05 , an approximate sample size required of 6 animals per group was calculated. Anticipating a larger variability of HT within ASA + CPG pretreated animals (not every pretreated mouse consequently developed HT) and to compensate for dead or excluded animals, we randomized a larger number of mice per group (Supplemental Table I).

Blinding procedure

Mice were randomly allocated to treatment groups based on a predetermined randomization table. Both the operating surgeon, as well as the researchers carrying out and evaluating the experiments were blinded as to treatment groups. This included encoding the images prior to measuring hemorrhage areas and infarct sizes.

$\mathrm{ASA}+\mathrm{CPG}$ pretreatment

Aspirin (Bayer Health Care, Morristown, NJ, USA) and Clopidogrel (Dr. Reddy's Laboratories Ltd., Beverley, UK) were given orally after an established protocol ${ }^{2}$. Briefly, tablets were crushed and dissolved in $300 \mathrm{~mL}$ drinking water (concentration: ASA $0.4 \mathrm{mg} / \mathrm{mL}$, clopidogrel $0.15 \mathrm{mg} / \mathrm{mL}$ ) and applied ad libitum for 72 hours. The drinking water was replaced every second day. 


\section{MCAO}

Animals were subjected to a standard filament MCAO model. After $2 \mathrm{hrs}$ of occlusion, the filament was withdrawn and all artery incisions were sealed to allow reperfusion. Where indicated, tPA (Boehringer Ingelheim, Ingelheim am Rhein, Germany) was then infused into the right jugular vein at a rate of $5 \mu \mathrm{l} /$ minute using a perfusion pump (Kent Scientific, Torrington, CT, USA). The tPA was dissolved to $4 \mathrm{mg} / \mathrm{ml}$ to achieve a dosage of $10 \mathrm{mg} / \mathrm{kg}$, the accepted standard dosage in rodents based on the lower activity of human TPA for rodent plasminogen $^{3}$. For low dose tPA treatment at $6.67 \mathrm{mg} / \mathrm{kg}$, analogous to the ENCHANTED trial but adjusted for the rodent metabolism, tPA was dissolved to $2.67 \mathrm{mg} / \mathrm{ml}$. Mice were anesthetized with $1.5 \%$ isoflurane mixed with $30 \%$ oxygen and $70 \%$ nitric oxidize. Its body temperature was maintained around $37^{\circ} \mathrm{C}$ with a heating pad monitored by a rectal temperature probe (CWE, Ardmore, PA, USA). An optic fiber probe was mounted onto the temporal bone of mouse head and blood flow was monitored with a laser Doppler system PeriFlux System 5000 (PeriMed, Ardmore, PA, USA). Skin under the neck was incised and the right-side artery system was exposed. A silicon coated filament $(0.19$ or $0.21 \mathrm{~mm}$, Doccol, Sharon, MA, USA) was inserted into external carotid artery (ECA) and advanced along internal carotid artery to block the MCA blood flow (to at least $20 \%$ lower than baseline). Total occlusion time was 2 hours, during which the mice were allowed to awaken to improve survival rates. Two hours later, the mice were re-anesthetized to achieve filament retrieval and reperfusion. After the surgery, mice were given buprenorphine (subcutaneously, $0.1 \mathrm{mg} / \mathrm{Kg}$, Reckitt Benckiser, Richmond, VA, USA) and proper food and water.

Outcome assessment

Deceased mice were considered with the maximal score of deficit regarding the neuroscore/neurologic behavior ( $\mathrm{NS}=4$ ), but were not included into the assessment of HT and ischemic lesion size. Neurologic outcome was evaluated 24 hours after MCAO by rating gait performance of the mice on a 5-point ordinal scale ( 0 : no apparent deficit, 1: hemiparesis while walking without circling, 2: mostly circling with some straight movement, 3 : fail to stand on feet or no movement at all, 4: deceased).

HT and infarct size determination

As the primary endpoint of our study we chose to quantify HT volume measured in brain sections. As a secondary objective, we studied the morphological features of HT and classified hemorrhages according to ECASS II morphologic definitions (Supplementary Table III). In this regard, we analyzed the hemorrhage location with respect to the site of the ischemic lesion. Following neurological outcome assessment, mice were anaesthetized and perfused transcardially with saline. Brains were extracted and sectioned into $1 \mathrm{~mm}$ thick coronal sections with a brain matrix and photographed. As primary outcome, the total intracerebral hemorrhage area was determined as the sum of hemorrhagic areas in coronal brain sections, measured using NIH ImageJ software. In the next step, we classified hemorrhages according to the ECASS II morphologic definitions ${ }^{4,5}$ adapted to animal models as used in previous publications ${ }^{6,7}$. Therefore, every section was individually scored on a 5 point ordinal scale (class I=no HT; II=hemorrhagic infarction type 1; III=hemorrhagic infarction type 2; IV=parenchymal hemorrhage type $1 ; \mathrm{V}=$ parenchymal hemorrhage type 2) and an overall grade for every brain was determined according to the highest grade occurring among the sections (Supplementary table II). To determine infarct size, brain sections were stained with $2 \%$ TTC (2,3,5-triphenyltetrazolium chloride) for 15 minutes in the dark and evaluated using the indirect infarct method (contralateral area minus non-infarcted area of the 
ipsilateral side). Location of hemorrhage-infarct mismatches was assessed by juxtaposing the hemorrhagic and ischemic areas of each section to obtain a hemorrhage-infarct profile for each brain.

Assessment of platelet function

In order to demonstrate ASA+CPG treatment efficacy we investigated platelet function separately in a subgroup of 15 mice ( 8 ASA+CPG pretreated mice vs. 7 untreated controls) not subjected to the previously described MCAO surgeries but receiving the same pretreatment paradigm. Platelet function was assessed in vitro using flow cytometry ${ }^{8-10}$ and in vivo with standard tail bleeding tests ${ }^{11,12}$ at the end of 3 days pretreatment.

Ex-vivo measurement of platelet function using flow cytometry

Animals were anesthetized with isoflurane (1.5\%) in a nitrous oxide/oxygen-mixture and placed on a heating pad. $90 \mu \mathrm{L}$ of venous blood were collected from the left jugular vein and mixed into sodium citrate (final $0.32 \%$ ). Platelet-rich plasma (PRP) was prepared by diluting whole blood 1:1 with PBS (containing 0.34\% sodium citrate) and performing centrifugation at $100 \mathrm{~g}$ for $10 \mathrm{~min}$, at room temperature. $35 \mu \mathrm{L}$ of PRP were then incubated with $15 \mu \mathrm{L}$ of vehicle (PBS containing $0.32 \%$ sodium citrate) or thrombin agonist solution (final $2 \mathrm{U} / \mathrm{ml}$ ) supplemented with $2.5 \mathrm{mM}$ GPRP and $6 \mathrm{mM} \mathrm{CaCl}_{2}$ for 5 minutes, gently shaking at $37^{\circ} \mathrm{C}$. Mouse PRP was then incubated with 1:100 dilution of CD41-FITC (platelet identifier) and CD62P-PE (platelet activation marker) monoclonal antibodies for 15 minutes at room temperature in the dark. Samples were then fixed with $650 \mu \mathrm{L}$ of fixative solution containing $0.2 \%$ formalin, $0.1 \%$ dextrose, and $0.2 \%$ BSA in PBS and analyzed using a BD LSRII Analyzer (BD Biosciences, Oxford, UK). FACS data were analysed with BD FACS DIVA software and FlowJo version 10 software. Mice were used further in tail bleeding tests. For part two of the study only $10 \mathrm{uL}$ of blood were collected and whole blood was used instead of PRP.

In vivo determination of platelet adhesion using standard tail bleeding tests

A distal 5mm segment of the tail was resected with a razor blade. The tail was immediately inserted into an Eppendorf tube containing $1 \mathrm{~mL}$ of prewarmed $\left(37^{\circ} \mathrm{C}\right)$ saline and the tube was incubated in a water bath $\left(37^{\circ} \mathrm{C}\right)$ to maintain tail temperature. The tail was removed from the microtube after 3 minutes. The blood sample was vortexed and ultrasound was applied to lyse erythrocyte cell membranes. The solution was then centrifuged for 30 minutes at 13,000 r.p.m. at $4^{\circ} \mathrm{C} .3 \times 100 \mu \mathrm{L}$ of the supernatant was transferred to $40 \mu \mathrm{L}$ of Drabkin's reagent on a 96 well plate and incubated for 15 minutes. Absorption at $540 \mathrm{~nm}$ was determined using a SpectraMax M5 photometer (Molecular Devices, San Jose, CA). Bleeding volumes were calculated using a standard curve.

Statistical analysis

Student's t test was used to compare normally distributed data between two data sets, the Mann-Whitney test when data was not distributed normally. One-way ANOVA with Tukey's or Kruskal Wallis tests were used to compare $\geq 3$ groups. All data were expressed as mean \pm SEM unless indicated otherwise. P-value $<0.05$ was considered significant. 


\section{Supplemental Tables}

\section{Supplemental Table I. Inclusion and exclusion criteria}

\begin{tabular}{|c|c|c|c|c|c|}
\hline Experimental group & $\begin{array}{l}\text { Included } \\
\text { mice (HT } \\
\text { assessment }\end{array}$ & $\begin{array}{l}\text { Excluded } \\
\text { mice } \\
\text { (deceased } \\
\text { mice were } \\
\text { excluded } \\
\text { from HT } \\
\text { assessment, } \\
\text { scored as } \\
\text { grade } 4 \\
\text { neurologic } \\
\text { behavior) }\end{array}$ & $\begin{array}{l}\text { Excluded } \\
\text { mice } \\
\text { (missing } \\
\text { doppler } \\
\text { decrease, } \\
\text { no stroke } \\
\text { in TTC) }\end{array}$ & $\begin{array}{l}\text { Excluded } \\
\text { mice } \\
\text { (surgical } \\
\text { error } \\
\text { during } \\
\text { MCAO } \\
\text { surgery) }\end{array}$ & $\begin{array}{l}\text { Total } \\
\text { mice }\end{array}$ \\
\hline \multicolumn{6}{|l|}{$\begin{array}{l}\text { Study part one 'ASA+CPG in } \\
\text { experimental stroke' }\end{array}$} \\
\hline Controls+MCAO & 10 & 2 & 0 & 1 & 13 \\
\hline $\mathrm{ASA}+\mathrm{CPG}+\mathrm{MCAO}$ & 9 & 2 & 1 & 0 & 12 \\
\hline Controls+MCAO+tPA & 7 & 1 & 0 & 0 & 8 \\
\hline $\mathrm{ASA}+\mathrm{CPG}+\mathrm{MCAO}+\mathrm{tPA}$ & 7 & 2 & 0 & 0 & 9 \\
\hline \multicolumn{6}{|l|}{$\begin{array}{l}\text { Study part two 'low dose tPA in } \\
\text { ASA+CPG stroke model' }\end{array}$} \\
\hline $\begin{array}{l}\text { Controls+MCAO+low } \\
\text { dose tPA }\end{array}$ & 8 & 4 & 1 & 0 & 13 \\
\hline $\begin{array}{l}\text { ASA+CPG+MCAO+low } \\
\text { dose tPA }\end{array}$ & 9 & 1 & 0 & 1 & 11 \\
\hline
\end{tabular}

$\mathrm{ASA}+\mathrm{CPG}=$ Aspirin and Clopidogrel $\mathrm{MCAO}=$ transient middle cerebral artery occlusion, $\mathrm{tPA}=$ tissue plasminogen activator. 
Supplemental Table II. Overall HT types ASA+CPG model

\begin{tabular}{|l|l|l|l|l|l|l|}
\hline Experimental group & $\begin{array}{l}\text { HT grade } \\
(1)=\text { non } \\
\text { hemorrhage }\end{array}$ & $\begin{array}{l}\text { HT } \\
\text { grade } \\
(2)= \\
\text { HI-1 }\end{array}$ & $\begin{array}{l}\text { HT } \\
\text { grade } \\
(3)= \\
\text { HI-2 }\end{array}$ & $\begin{array}{l}\text { HT } \\
\text { grade } \\
(4)= \\
\text { PH-1 }\end{array}$ & $\begin{array}{l}\text { HT } \\
\text { grade } \\
(5)= \\
\text { PH-2 }\end{array}$ & $\begin{array}{l}\text { Sum } \\
\text { (mice } \\
\text { total) }\end{array}$ \\
\hline MCAO & 5 & 5 & 0 & 0 & 0 & 10 \\
\hline ASA+CPG+MCAO & 1 & 4 & 0 & 4 & 0 & 9 \\
\hline MCAO+tPA & 3 & 3 & 1 & 0 & 0 & 7 \\
\hline ASA+CPG+MCAO+tPA & 0 & 2 & 0 & 3 & 2 & 7 \\
\hline
\end{tabular}

$\mathrm{MCAO}=$ transient middle cerebral artery occlusion; $\mathrm{ASA}+\mathrm{CPG}=$ Aspirin and Clopidogrel; $\mathrm{HT}=$ Hemorrhagic Transformation; $\mathrm{HI}=$ Hemorrhagic infarction; $\mathrm{PH}=$ Parenchymal hematoma; $\mathrm{tPA}=$ tissue plasminogen activator. 


\section{Supplemental Table III. Hemorrhage classification based on ECASS morphologic}

definitions of sIHC $^{4}$

\begin{tabular}{|l|l|}
\hline Grade & Definition \\
\hline I & Non hemorrhage \\
\hline II & $\begin{array}{l}\text { Hemorrhagic infarction type 1 (HI-1), defined as small petechiae, generally along } \\
\text { the boundary of the infarct }\end{array}$ \\
\hline III & $\begin{array}{l}\text { Hemorrhagic infarction type 2 (HI-2), with more confluent petechiae within the } \\
\text { damaged area }\end{array}$ \\
\hline IV & $\begin{array}{l}\text { Parenchymal hematoma type 1 (PH-1), characterized by blood clots in }<30 \% \text { of } \\
\text { the injured parenchyma }\end{array}$ \\
\hline V & Parenchymal hematoma type 2 $(\mathrm{PH}-2)$ with clots in $>30 \%$ of the infarct \\
\hline
\end{tabular}

$\mathrm{HI}=$ Hemorrhagic infarction; $\mathrm{PH}=$ Parenchymal hematoma. 
Supplemental Figures

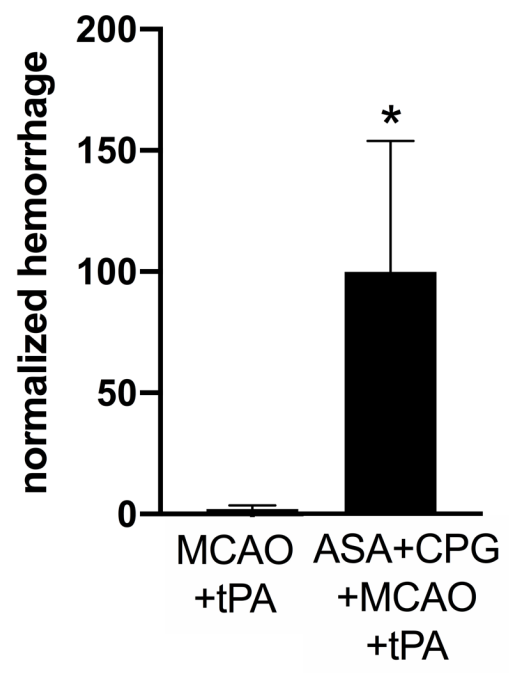

Supplemental Figure I. Preliminary experiments in ASA+CPG model. Control mice total hemorrhage (combined brain surface and sections measurements) was $2.2 \pm 1.4 \%$ of the total hemorrhage determined in $\mathrm{ASA}+\mathrm{CPG}$ mice. 


\section{Supplemental References}

1. Robinson TG, Wang X, Arima H, Bath PM, Billot L, Broderick JP, et al. Low-Versus Standard-Dose Alteplase in Patients on Prior Antiplatelet Therapy the ENCHANTED Trial (Enhanced Control of Hypertension and Thrombolysis Stroke Study). Stroke. 2017;48(7):1877-1883.

2. Lauer A, Schlunk F, Van Cott EM, Steinmetz H, Lo EH, Foerch C. Antiplatelet pretreatment does not increase hematoma volume in experimental intracerebral hemorrhage. J Cereb Blood Flow Metab. 2011;31(8):1736-1742.

3. Korninger C, Collen D. Studies on the specific fibrinolytic effect of human extrinsic (tissue-type) plasminogen activator in human blood and in various animal species in vitro. Thromb Haemost. 1981;46:561-565.

4. Von Kummer R, Broderick JP, Campbell BCV, Demchuk A, Goyal M, Hill MD, et al. The heidelberg bleeding classification: Classification of bleeding events after ischemic stroke and reperfusion therapy. Stroke. 2015;46(10):2981-2986.

5. Yaghi S, Willey JZ, Cucchiara B, Goldstein JN, Gonzales NR, Sheth KN, et al. Treatment and Outcome of Hemorrhagic Transformation After Intravenous Alteplase in Acute Ischemic Stroke: A Scientific Statement for Healthcare Professionals From the American Heart Association/American Stroke Association. Stroke. 2017;48(12):e343-e361.

6. García-Yébenes I, Sobrado M, Zarruk JG, Castellanos M, Pérez de la Ossa N, Dávalos A, et al. A mouse model of hemorrhagic transformation by delayed tissue plasminogen activator administration after in situ thromboembolic stroke. Stroke. 2011;42(1):196203.

7. Copin J-C, Gasche Y. Effect of the duration of middle cerebral artery occlusion on the risk of hemorrhagic transformation after tissue plasminogen activator injection in rats. Brain Res. 2008;1243:161-166.

8. Armstrong PCJ, Kirkby NS, Chan MV, Finsterbuch M, Hogg N, Nourshargh S, et al. Novel whole blood assay for phenotyping platelet reactivity in mice identifies ICAM-1 as a mediator of platelet-monocyte interaction. Blood. 2015;126(10):e11-e18.

9. De Cuyper IM, Meinders M, van de Vijver E, de Korte D, Porcelijn L, de Haas M, et al. A novel fl ow cytometry - based platelet aggregation assay. Blood. 2013;121(10):70-80.

10. Van Velzen JF, Laros-Van Gorkom BAP, Pop GAM, Van Heerde WL. Multicolor flow cytometry for evaluation of platelet surface antigens and activation markers. Thromb Res. 2012;130(1):92-98.

11. Saito MS, Lourenço AL, Kang HC, Rodrigues CR, Cabral LM, Castro HC, et al. New approaches in tail-bleeding assay in mice: improving an important method for designing new anti-thrombotic agents. Int J Exp Pathol. 2016;97(3):285-292.

12. Liu Y. Jennings NL, Dart AM, Du XJ. Standardizing a simpler, more sensitive and accurate tail bleeding assay in mice. World J Exp Med. 2012;2(2):30. 
9 Manuskript "Thrombolysis in acute stroke under dual antiplatelet therapy: Perspectives arising from translational studies" 


\section{Thrombolysis in acute stroke under dual antiplatelet therapy: perspectives arising from translational studies}

Franziska Lieschke, Yi Zheng, Christian Foerch, Klaus van Leyen ${ }^{*}$

We have recently established a mouse model of focal stroke under dual antiplatelet therapy (DAPT) to study tissue plasminogen activator (tPA)-associated hemorrhagic transformation. The purpose of this shor perspective is to discuss the rationale fo establishing the model, highlighting its relevance for addressing unresolved clinica questions. Hemorrhagic conversion of the ischemic stroke remains one of the major liabilities of thrombolytic therapy with tPA contributing to unfavorable outcomes and failed regeneration. This was recognized early on, and the resulting restrictions on tPA usage have led to only a minor percentage of stroke patients receiving any kind of drug treatment to limit ischemic injury. Broadening the patient population eligible for thrombolytic therapy is a major goal, and thus efforts are being directed at optimally defining inclusion criteria based on prior drug treatment status, among other factors. DAPT with aspirin and clopidogrel (ASA + CPG) is commonly given to patients at high risk for atherothrombotic events. However, clinical data to date has not been entirely clear as to whether the increased likelihood of bleeding following thrombolysis in patients on DAP is indeed detrimental to patient outcome and many see this potential downside outweighed by the benefits of recanalization of the blocked vessel. Accordingly, current guidelines allow for tPA thrombolysis in patients under DAPT. Nonetheless, doubts remain if on balance tPA is actually beneficia in these patients, and these doubts may lead to undertreatment. Final clarity might be achieved with a prospective, randomized clinical trial, but it appears unlikely that this will ever occur. In this situation, modeling the process in animals subjected to experimental ischemic stroke under DAPT can provide insights into mechanisms of hemorrhagic transformation (HT). Even more importantly, establishing such a model enables researchers to test possible strategies to mitigate the bleeding risk in patients on DAPT. If the safety of tPA thrombolysis can be increased by reducing hemorrhage, this could clearly tilt the balance towards favoring tPA treatment, and thus improve long-term outcomes of ischemic strokes. Testing such an approach in the animal model is the best first step in evaluating the utility of such an adjuvant.

Current use of dual antiplatelet therapy: DAPT is used to prevent atherothrombotic events in high risk patients, for example in patients with acute coronary syndrome with or without percutaneous coronary intervention, as well as in percutaneous coronary intervention patients without acute cardiac symptoms. Aspirin is combined with a P2Y12 inhibitor such as Clopidogrel, Ticagrelor, or Prasugrel and should be continued for up to one year. Furthermore DAPT is increasingly used as secondary prevention following acute ischemic stroke of atherothrombotic origin within the first 24 hours after stroke onset: Following high risk transient ischemic attack or minor stroke DAPT with preferably ASA + CPG is continued for 10 to 21 days. Another clinical scenario of relevance is DAPT in acute stroke patients with a tandem occlusion of the internal carotid artery and the middle cerebral artery. If those patients are subjected to endovascular treatment, stent implantation into the proximal internal carotid artery is necessary to allow passage with the retriever system. Here again, DAPT with ASA + CPG is indicated to prevent re-occlusion after stenting, although many of the patients have been treated with tPA just minutes before. Before, during and after artery stenting, it is recommended to continue the DAPT for $1-3$ months.

Clinical studies on pre-stroke DAPT and increased HT following tPA thrombolysis: Multiple retrospective analyses on pre-stroke antiplatelet treatment and tPA thrombolysis in acute stroke patients indicated a simila long-term survival and functional outcome compared to patients without antiplatele medical history, despite the significantly increased risk of symptomatic intracrania hemorrhage $(\mathrm{sICH})$. In those studies, the hemorrhagic outcome was classified by both imaging characteristics and clinical presentation. As such, Diedler et al. (2010) analyzed the data of 11,865 patients collected in the Safe Implementation of Treatments in Stroke International Stroke Thrombolysis Register from 2002-2007, which included 151 patients on DAPT with ASA + CPG. While in their multivariable analysis, ASA + CPG was associated with increased risk for $\mathrm{sICH}$, no significant differences in mortality and functional outcome at 3 months were found between patients on prior antiplatelet medication compared to antiplatelet naïve patients (Diedler et al., 2010). In contrast, a metaanalysis by Pan et al. (2015) including 11 studies with a total of 19,453 patients confirmed the increased $\mathrm{sICH}$ risk fo patients on pre-stroke DAPT but claimed trend toward reduced probability of good functional outcome in patients on pre stroke antiplatelets (all types together) although this finding was not statistically significant. Another meta-analysis by Luo et al. (2016) included 19 studies and reported a confounder-adjusted positive association between pre-stroke antiplatelets (any kind) and $\mathrm{slCH}$, with no differences in mortality and functional outcome. Their subgroup analysis revealed, that among all antiplatelets, patients on DAPT with ASA + CPG were at highest risk for $\mathrm{sICH}$. Xian et al. (2016) performed an analysis on the data collected in the American Heart Association and American Stroke Association Get With the Guidelines Stroke registry including 2397 patients on prior DAPT with ASA + CPG, which replicated the increased odds of sICH for DAPT patients in unadjusted and risk adjusted models, but demonstrated a similar mortality and even better functional outcomes in these patients. Finally, Tsivgoulis et al. (2018) recently reported anothe retrospective analysis on the data collected in the Safe Implementation of Treatments in Stroke International Stroke Thrombolysis Register from 2010-2017 focusing on particularly DAPT. After balancing groups (antiplatelet naïve versus prior DAPT) for all baseline characteristics, sICH rates were significantly higher in DAPT patients, while 3-month outcomes (mortality and functional outcome) did not differ (Tsivgoulis et al. 2018). The accumulating data eventually led to the elimination of pre-stroke DAPT as a contraindication for tPA thrombolysis. However, there are potentially importan long-term cognitive effects. Cerebral microbleeds have been linked to a decline in various cognitive and executive functions (Weekman et al., 2016; Moulin and Cordonnier, 2019). Although this question has to date not been conclusively studied for HT under DAPT, it stands to reason that the observed sICH may lead to even more severe cognitive effects. This type of long term brain injury is not captured in the aforementioned clinical outcome studies, which rely on assessments after several months and which often only asses the independency in daily activities (e.g., modified Rankin Scale) as a measure for the degree of disability. Cognitive functions such as attention, executive functioning, learning and memory, language and social cognition are usually not queried. Avoiding HT could thus increase the benefit of tPA in patients on pre-stroke DAPT both by tipping the balance clearly towards bigger benefits of tPA in the functional outcomes at 3 months, and by also reducing the risk of long term cognitive decline and dementia.

Experimental stroke model of DAPTrelated HT: A prospective randomized clinical trial evaluating whether the benefit of tPA outweighs the increased risk of HT in patients on pre-stroke DAPT would contribute to final clarity, but is difficult to conceptualize, especially because tPA thrombolysis is now increasingly combined with mechanical thrombectomy. At this point, animal models can be interesting. Beyond the fact that rodent studies can be conducted in a controlled environment and under standardized conditions, there are two major reasons why establishing an animal model of DAPT-related HT is of value: 1) While the aforementioned clinical studies tell us something about the risks and benefits associated with thrombolysis under DAPT, they provide very little insight nto mechanisms of HT. Here, animal 


\section{Perspective}

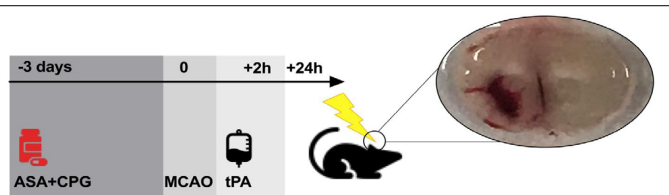

Figure 1 | Model of HT treated with ASA + CPG in ischemic stroke.

Mice were fed with ASA + CPG for 3 days, and subsequently subjected to transient MCAO for 2 hours. At the time point of reperfusion, tPA was infused intravenously if indicated. 24 hours after stroke onset, mice were sacrificed and outcome parameters, in particular brain hemorrhages were assessed. ASA + CPG: Aspirin and clopidogrel; HT: hemorrhagic transformation; MCAO: transient middle cerebral artery; tPA: tissue plasminogen activator.

studies provide a way forward, by allowing the researcher to study physiological and molecular correlates of brain injury. 2) Moreover and perhaps more importantly for the clinician, they provide a platform for testing novel ideas to reduce $\mathrm{HT}$, by treating mice with possible neuroprotective or vasculoprotective therapies.

An extensive literature search did not reveal any existing animal models of pre-stroke DAPT in ischemic stroke. We therefore established an experimental stroke model of tPA treatment under DAPT in mice, successfully demonstrating increased levels of HT in mice treated with ASA + CPG prior to experimental stroke and thrombolytic therapy (Zheng et al., 2019). A major advantage of this model is the incorporation of FACS-based platelet activation measurements, allowing the platelet status of each individual mouse to be determined (Lieschke et al., 2020). For this, mice were fed with ASA + CPG diluted in their drinking water. After 3 days, blood was collected and tested in vitro using flow cytometry analysis of platelet activation markers. Mice were then subjected to 2 hours of middle cerebral artery occlusion followed by tPA infusion into the jugular vein. At 24 hours after the onset of ischemia, mice were sacrificed and the HT was assessed on brain sections (Figure 1). To our knowledge, this is the first study investigating the effects of DAPT in an experimental stroke model. We succeeded in effectively treating mice with ASA + CPG via drinking water, and achieved significant antithrombotic effects measured in vitro using flow cytometry. Furthermore, we demonstrated the feasibility to perform surgical procedures associated with the middle cerebral artery occlusion model inowing to the antithrombotic treatmentvulnerable and fragile tissue without increasing the amount of complications resulting from the surgical intervention itself. Our model can now be used to identify novel mechanisms of HT, and to develop strategies to reduce bleeding. Ultimately, the development of those strategies could further increase the benefit of tPA thrombolysis.

Ideally, adjunctive treatments could be used in a multimodal therapy in the future, maintaining the efficacy of pharmacological or mechanical thrombolysis. Possible candidates that stabilize the blood-brain barrier could be modulators of inflammation, as well as agents that reduce oxidative stress. In this context, inhibiting 12/15-lipoxygenase could be a promising approach, since this enzyme is upregulated in neurons and vascular endothelial cells in the peri-infarct region after experimental stroke. Both gene knockout and pharmacological inhibition of 12/15-lipoxygenase with agents including LOXBlock-1 or ML351 were shown to reduce HT in different contexts (Liu et al., 2017; Karatas et al., 2018). It remains to be seen whether the protection by this promising candidate will be confirmed in our mouse model of tPA thrombolysis under DAPT.

As with all models, there are limitations to consider. First, while DAPT in patients is most commonly initiated in the hospital following a first atherothrombotic event, the timepoint and duration of DAPT in animal models is set artificially not always perfectly reflecting the clinical scenario. Second, real patients, especially those on DAPT, more often suffer from several comorbidities that complicate the overall situation of the patient. Hemorrhagic conversion was found to typically occur in elderly patients (Diedler et al., 2010; Xian et al., 2016), whereas animals used in experimental studies are usually young and healthy and all experiments are conducted under controlled environmental and standardized conditions. Third, longterm outcome studies in animals are difficult. With most protocols, high mortality rates can be expected when extending the recovery period beyond several days.

To conclude, until neuro- and vasculoprotective candidates can be tested in clinical trials, animal models remain one helpful tool in establishing stroke treatment. Ultimately, these studies may lead to a safer application of tPA in a larger patient population than currently reached and may significantly improve the riskbenefit assessment in acute stroke treatment, eventually leading to improved long-term outcomes of ischemic strokes.

This work was supported by American Heart Association (17GRNT33460100 to KL) and Faculty of Medicine, Goethe University Frankfurt (FPF doctoral scholarship to FL).

\section{Franziska Lieschke, Yi Zheng,}

Christian Foerch, Klaus van Leyen*

Massachusetts General Hospital, Harvard Medical School, Charlestown, MA, USA (Lieschke F, Zheng Y, Foerch $\mathrm{C}$, van Leyen $\mathrm{K}$ )

Department of Neurology, University Hospital Frankfurt, Goethe-University, Frankfurt am Main, Germany (Lieschke F, Foerch C)

${ }^{*}$ Correspondence to: Klaus van Leyen, $\mathrm{PhD}$,

klaus vanleven@hms.harvard.edu.

https://orcid.org/0000-0003-1032-3754

(Klaus van Leyen)

Received: February 14, 2020

Peer review started: February 20, 2020
Accepted: April 7, 2020

Published online: August 10, 2020

\section{https://doi.org/10.4103/1673-5374.284906}

How to cite this article: Lieschke F, Zheng Y, Foerch

$C$, van Leyen K (2021) Thrombolysis in acute stroke under dual antiplatelet therapy: perspectives arising from translational studies. Neural Regen Res 16(1):113-114.

Copyright license agreement: The Copyright License Agreement has been signed by all authors before publication.

Plagiarism check: Checked twice by iThenticate. Peer review: Externally peer reviewed.

Open access statement: This is an open access journal, and articles are distributed under the terms of the Creative Commons AttributionNonCommercial-ShareAlike 4.0 License, which allows others to remix, tweak, and build upon the work non-commercially, as long as appropriate credit is given and the new creations are licensed under the identical terms.

\section{References}

Diedler J, Ahmed N, Sykora M, Uyttenboogaart M, Overgaard K, Luijckx GJ, Soinne L, Ford GA, Lees KR, Wahlgren N, Ringleb P (2010) Safety of intravenous thrombolysis for acute ischemic stroke in patients receiving antiplatelet therapy at stroke onset. Stroke 41:288-294.

Karatas H, Eun Jung J, Lo EH, van Leyen K (2018) Inhibiting 12/15-lipoxygenase to treat acute stroke in permanent and tPA induced thrombolysis models. Brain Res 1678:123-128.

Lieschke F, Zheng Y, Schaefer JH, van Leyen K, Foerch C (2020) Measurement of platelet function in an experimental stroke model with aspirin and clopidogrel treatment. Front Neurol 11:85

Liu Y, Zheng $\mathrm{Y}$, Karatas $\mathrm{H}$, Wang $\mathrm{X}$, Foerch C, Lo EH, va Leyen K (2017) 12/15-Lipoxygenase inhibition or knockout reduces warfarin-associated hemorrhagic transformation after experimental stroke. Stroke 48:445-451.

Luo S, Zhuang M, Zeng W, Tao J (2016) Intravenous Thrombolysis for acute ischemic stroke in patient receiving antiplatelet therapy: a systematic review and meta-analysis of 19 studies. J Am Heart Assoc doi: 10.1161/JAHA.116.003242.

Moulin S, Cordonnier C (2019) Role of cerebra microbleeds for intracerebral haemorrhage and dementia. Curr Neurol Neurosci Rep 19:51.

Pan X, Zhu Y, Zheng D, Liu Y, Yu F, Yang J (2015) Prior antiplatelet agent use and outcomes after intravenous thrombolysis with recombinant tissue plasminogen activator in acute ischemic stroke: a meta-analysis of cohort studies and randomized controlled trials. Int Stroke 10:317-323.

Tsivgoulis G, Katsanos AH, Mavridis D, Gdovinova Z, Karlinski M, Macleod MJ, Strbian D, Ahmed N (2018) Intravenous thrombolysis for ischemic stroke patients on dual antiplatelets. Ann Neurol 84:89-97.

Weekman, Erica M. and Wilcock, Donna M (2016) Matrix metalloproteinase in blood-brain barrier breakdown in dementia. J Alzheimers Dis 49:893-903.

Xian Y, Federspiel JJ, Grau-Sepulveda M, Hernandez AF, Schwamm LH, Bhatt DL, Smith EE, Reeves MJ, Thomas L, Webb L, Bettger JP, Laskowitz DT, Fonarow GC, Peterson ED (2016) Risks and benefits associated with prestroke antiplatelet therapy among patients with prestroke antiplatelet therapy among patients with
acute ischemic stroke treated with intravenous tissue acute ischemic stroke treated with intravenous
plasminogen activator. JAMA Neurol 73:50-59.

Zheng Y, Lieschke F, Schaefer JH, Wang X, Foerch C, van Leyen K (2019) Dual antiplatelet therapy increases hemorrhagic transformation following thrombolytic treatment in experimental stroke. Stroke 50:36503653

C-Editors: Zhao M, Li JY; T-Editor: Jia Y

114 | NEURAL REGENERATION RESEARCH | Vol 16 | No.1 | January 2021 


\section{Literaturverzeichnis zu den Zitaten des „Comprehensive}

\section{summary"}

1. Wang $\mathrm{H}$, Naghavi $\mathrm{M}$, Allen $\mathrm{C}$, et al. Global, regional, and national life expectancy, allcause mortality, and cause-specific mortality for 249 causes of death, 1980-2015: a systematic analysis for the Global Burden of Disease Study 2015. Lancet. 2016;388(10053):1459-1544. doi:10.1016/S0140-6736(16)31012-1

2. Destatis R. Gesundheit in Deutschland. Gesundheitsberichterstattung des Bundes. Robert Koch-Institut (Hrsg). 2015. doi:10.17886/rkipubl-2015-003

3. Foerch C, Misselwitz B, Sitzer M, Steinmetz H, Neumann-Haefelin T. Die Schlaganfallzahlen bis zum Jahr 2050. Dtsch Arztebl. 2008;105(26):467-473. doi:10.3238/arztebl.2008.0467

4. Donnan GA, Fisher M, Macleod M, Davis SM. Stroke. Lancet. 2008;371(9624):16121623. doi:https://doi.org/10.1016/S0140-6736(08)60694-7

5. Powers WJ, Rabinstein AA, Ackerson T, et al. 2018 Guidelines for the Early Management of Patients With Acute Ischemic Stroke: A Guideline for Healthcare Professionals From the American Heart Association/American Stroke Association. Vol 49.; 2018. doi:10.1161/STR.0000000000000158

6. The European Stroke Organisation (ESO) Executive Committee and the ESO Writing Committee. Guidelines for Management of Ischaemic Stroke and Transient Ischaemic Attack 2008. Cerebrovasc Dis. 2008;25(5):457-507. doi:10.1159/000131083

7. Pan X, Zhu Y, Zheng D, Liu Y, Yu F, Yang J. Prior Antiplatelet Agent Use and Outcomes after Intravenous Thrombolysis with Recombinant Tissue Plasminogen Activator in Acute Ischemic Stroke: A Meta-Analysis of Cohort Studies and Randomized Controlled Trials. Int J Stroke. 2014;10(3):317-323. doi:10.1111/ijs.12431

8. Wahlgren N, Ahmed N, Dávalos A, et al. Thrombolysis with alteplase for acute ischaemic stroke in the Safe Implementation of Thrombolysis in Stroke-Monitoring Study (SITSMOST): an observational study. Lancet. 2007;369(9558):275-282. doi:10.1016/S01406736(07)60149-4

9. Xian Y, Federspiel JJ, Grau-Sepulveda M, et al. Risks and benefits associated with prestroke antiplatelet therapy among patients with acute ischemic stroke treated with intravenous tissue plasminogen activator. JAMA Neurol. 2016;73(1):50-59. doi:10.1001/jamaneurol.2015.3106

10. Diedler J, Ahmed N, Sykora M, et al. Safety of intravenous thrombolysis for acute ischemic stroke in patients receiving antiplatelet therapy at stroke onset. Stroke. 2010;41(2):288-294. doi:10.1161/STROKEAHA.109.559724

11. Tsivgoulis G, Goyal N, Kerro A, et al. Dual antiplatelet therapy pretreatment in IV thrombolysis for acute ischemic stroke. Neurology. 2018;91(11):e1067 LP-e1076. doi:10.1212/WNL.0000000000006168

12. Corriveau RA, Bosetti F, Emr M, et al. The Science of Vascular Contributions to Cognitive Impairment and Dementia (VCID): A Framework for Advancing Research Priorities in the Cerebrovascular Biology of Cognitive Decline. Cell Mol Neurobiol. 2016;36(2):281-288. doi:10.1007/s10571-016-0334-7

13. Strbian D, Engelter $S$, Michel $P$, et al. Symptomatic intracranial hemorrhage after stroke thrombolysis: The SEDAN Score. Ann Neurol. 2012;71(5):634-641. doi:10.1002/ana.23546

14. Moulin S, Cordonnier C. Role of Cerebral Microbleeds for Intracerebral Haemorrhage and Dementia. Curr Neurol Neurosci Rep. 2019;19(8):51. doi:10.1007/s11910-019-0969-0

15. Weekman EM, Wilcock DM. Matrix Metalloproteinase in Blood-Brain Barrier Breakdown in Dementia. J Alzheimer's Dis. 2016;49:893-903. doi:10.3233/JAD-150759 
16. Saraf S, Bensalha I, Gorog DA. Antiplatelet resistance - Does it exist and how to measure it? Clin Med Cardiol. 2009;2009(3):77-91. doi:10.4137/cmc.s2159

17. Floyd CN, Ferro A. Antiplatelet drug resistance: Molecular insights and clinical implications. Prostaglandins Other Lipid Mediat. 2015;120:21-27. doi:https://doi.org/10.1016/j.prostaglandins.2015.03.011

18. Al-Husein BA, Al-Azzam SI, Alzoubi KH, Khabour OF, Nusair MB, Alzayadeen S. Investigating the Effect of Demographics, Clinical Characteristics, and Polymorphism of MDR-1, CYP1A2, CYP3A4, and CYP3A5 on Clopidogrel Resistance. J Cardiovasc Pharmacol. 2018;72(6).

https://journals.Iww.com/cardiovascularpharm/Fulltext/2018/12000/Investigating_the_Effe ct_of_Demographics,_Clinical.6.aspx.

19. Uchino K, Alexandrov A V., Garami Z, El-Mitwalli A, Morgenstern LB, Grotta JC. Safety and feasibility of a lower dose intravenous TPA therapy for ischemic stroke beyond the first three hours. Cerebrovasc Dis. 2005;19(4):260-266. doi:10.1159/000084090

20. Deguchi I, Tanahashi N, Takao M. Clinical Study of Intravenous, Low-Dose Recombinant Tissue Plasminogen Activator for Acute Cerebral Infarction: Comparison of Treatment within 3 Hours versus 3-4.5 Hours. J Stroke Cerebrovasc Dis. 2018;27(4):1033-1040. doi:10.1016/j.jstrokecerebrovasdis.2017.11.009

21. Liu H, Zheng H, Cao Y, et al. Low- versus Standard-Dose Intravenous Tissue-Type Plasminogen Activator for Acute Ischemic Stroke: An Updated Meta-Analysis. J Stroke Cerebrovasc Dis. 2018;27(4):988-997. doi:10.1016/j.jstrokecerebrovasdis.2017.11.005

22. Kim BJ, Han MK, Park TH, et al. Low-Versus Standard-Dose Alteplase for Ischemic Strokes Within 4.5 Hours: A Comparative Effectiveness and Safety Study. Stroke. 2015;46(9):2541-2548. doi:10.1161/STROKEAHA.115.010180

23. Robinson TG, Wang X, Arima H, et al. Low-Versus Standard-Dose Alteplase in Patients on Prior Antiplatelet Therapy the ENCHANTED Trial (Enhanced Control of Hypertension and Thrombolysis Stroke Study). Stroke. 2017;48(7):1877-1883. doi:10.1161/STROKEAHA.116.016274

24. Jin G, Arai K, Murata Y, et al. Protecting against cerebrovascular injury: Contributions of 12/15-lipoxygenase to edema formation after transient focal ischemia. Stroke. 2008;39(9):2538-2543. doi:10.1161/STROKEAHA.108.514927

25. Yigitkanli K, Pekcec A, Karatas H, et al. Inhibition of 12/15-lipoxygenase as therapeutic strategy to treat stroke. Ann Neurol. 2013;73(1):129-135. doi:10.1002/ana.23734

26. Yaghi S, Willey JZ, Cucchiara B, et al. Treatment and Outcome of Hemorrhagic Transformation After Intravenous Alteplase in Acute Ischemic Stroke: A Scientific Statement for Healthcare Professionals From the American Heart Association/American Stroke Association. Stroke. 2017;48(12):e343-e361. doi:10.1161/STR.0000000000000152

27. Zheng Y, Lieschke F, Schaefer JH, Wang X, Foerch C, van Leyen K. Dual Antiplatelet Therapy Increases Hemorrhagic Transformation Following Thrombolytic Treatment in Experimental Stroke. Stroke. 2019;50(12):3650-3653. doi:10.1161/strokeaha.119.027359

28. Lieschke F, Zheng Y, Schaefer JH, van Leyen K, Foerch C. Measurement of Platelet Function in an Experimental Stroke Model With Aspirin and Clopidogrel Treatment . Front Neurol . 2020;11:85. https://www.frontiersin.org/article/10.3389/fneur.2020.00085.

29. Finsterbusch M, Schrottmaier WC, Kral-Pointner JB, Salzmann M, Assinger A. Measuring and interpreting platelet-leukocyte aggregates. Platelets. 2018;29(7):677-685. doi:10.1080/09537104.2018.1430358

30. Harrison P, Martin Cramer E. Platelet a-granules. Blood Rev. 1993;7(1):52-62. doi:https://doi.org/10.1016/0268-960X(93)90024-X

31. Liu Y, Zheng Y, Karatas H, et al. 12/15-Lipoxygenase Inhibition or Knockout Reduces Warfarin-Associated Hemorrhagic Transformation after Experimental Stroke. Stroke. 2017;48(2):445-451. doi:10.1161/STROKEAHA.116.014790 
32. Karatas H, Eun Jung J, Lo EH, van Leyen K. Inhibiting 12/15-lipoxygenase to treat acute stroke in permanent and tPA induced thrombolysis models. Brain Res. 2018;1678:123128. doi:10.1016/j.brainres.2017.10.024

33. Van Leyen K, Kim HY, Lee SR, Jin G, Arai K, Lo EH. Baicalein and 12/15-lipoxygenase in the ischemic brain. Stroke. 2006;37(12):3014-3018.

doi:10.1161/01.STR.0000249004.25444.a5 


\section{Anhang}

\subsection{Does ML351 affect tPA/plasmin activity?}

\section{Objective}

An additional question, we have been working on, is the pharmacological interaction of ML351 with tPA. In order to rule out, that the observed effect of ML351 reducing HT in our ASA+CPG model was due to an inhibition of tPA, we performed an in-vitro plasmin activity assay.

\section{Methods}

This assay is based on the ability of plasmin to proteolytically cleave a synthetic plasmin substrate (an AMC—conjugated peptide) and thereby releasing the fluorophore (AMC), which can be easily detected and quantified with a regular plate reader.

We added ML351 and tPA to plasminogen and the AMC-conjugated plasmin substrate. Upon plasminogen activation via cleavage by functional tPA, plasmin activity leads to an increased AMC signal detection due to the increasing release of the fluorophore from its conjugated peptide.

\section{Results}

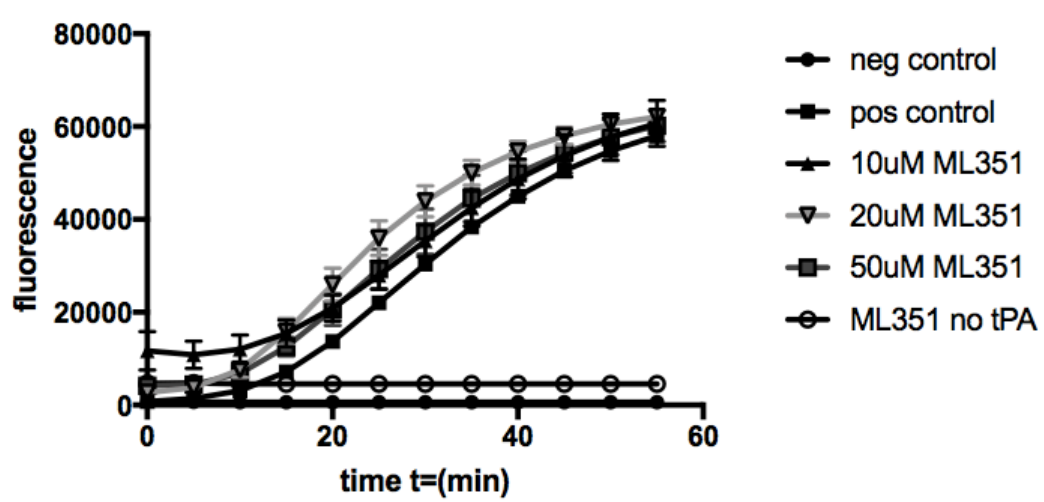

Figure: ML351 did not change tPA activity. Neg. control lacks tPA, positive control without ML351. Moreover, ML351 alone is not able to cleave plasminogen in the absence of tPA (ML351 no tPA). 
When IPA was added to plasminogen and the AMC-conjugated plasmin substrate, the AMC signal increased with time (positive control). Also in the presence of 10, 20 and 50 UM of ML351, the AMC signal increased. As intended, the negative control (leaving out tPA) showed no increase in AMC signal intensity. Moreover ML351 itself is not able to activate plasminogen.

\section{Conclusion}

ML351 did not interact with or inhibited tPA activity. 


\subsection{Visual Abstract of "Dual antiplatelet therapy increases hemorrhagic transformation following thrombolytic treatment in experimental stroke"}
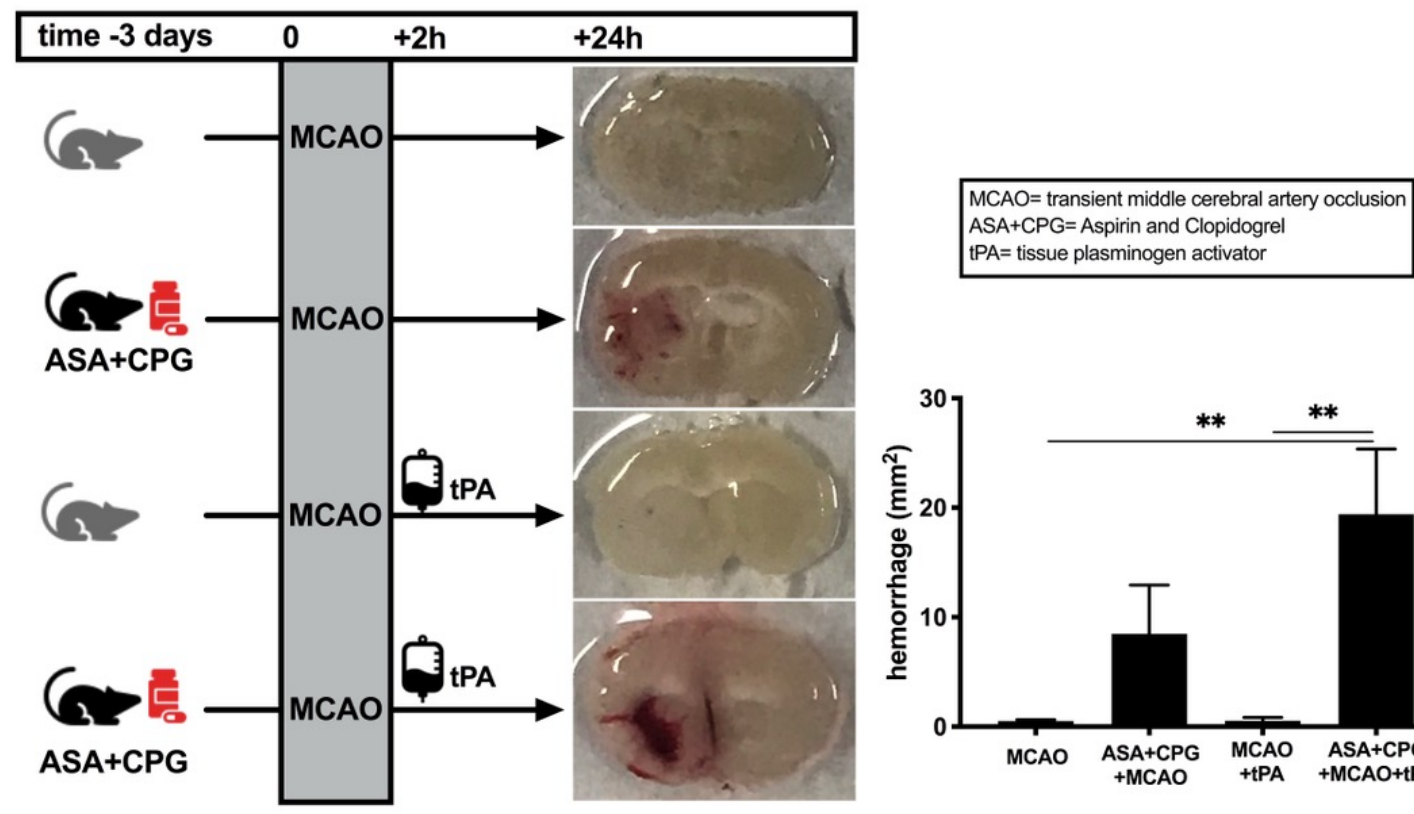

In a new mouse model of ischemic stroke under dual antiplatelet therapy, tPA increases hemorrhagic transformation. To establish the model, mice were subjected to experimental stroke in four groups:

1. MCAO only

2. $72 \mathrm{~h}$ pretreatment with $\mathrm{ASA}+\mathrm{CPG}$, followed by MCAO

3. MCAO followed by infusion of tPA

4. $72 \mathrm{~h}$ pretreatment with $\mathrm{ASA}+\mathrm{CPG}$, followed by $M C A O$ and infusion of $\mathrm{TPA}$

Group 4 showed significantly elevated levels of hemorrhage $24 \mathrm{~h}$ after MCAO, compared with groups 1 and $3\left({ }^{* *} p<0.01\right)$. Lowering the tPA dosage did not change the outcome in this model. 


\subsection{Supplemental methods of "12/15-LOX-inhibition in ASA+CPG model"}

\section{Pre-planning}

Sample size calculations were based on our previous studies in this model. Death prior to the end of the experiment, the insufficient occlusion of the right MCA (indicated by missing cerebral blood flow decrease in combination with an ischemic lesion size smaller than minus twice the SD of the mean ischemic lesion size) and surgical errors during the MCAO operation (causing insatiable bleeding) led to exclusion from evaluation.

\begin{tabular}{|l|l|l|l|l|l|}
\hline $\begin{array}{l}\text { Experimental } \\
\text { group }\end{array}$ & $\begin{array}{l}\text { Included } \\
\text { mice }\end{array}$ & $\begin{array}{l}\text { Excluded } \\
\text { mice due to } \\
\text { death prior } \\
\text { to the end } \\
\text { of the } \\
\text { experiment }\end{array}$ & $\begin{array}{l}\text { Excluded } \\
\text { mice no } \\
\text { stroke in } \\
\text { TTC/ } \\
\text { missing } \\
\text { doppler } \\
\text { decrease }\end{array}$ & $\begin{array}{l}\text { Excluded } \\
\text { mice due to } \\
\text { surgical } \\
\text { error and } \\
\text { insatiable } \\
\text { bleeding }\end{array}$ & Total mice \\
\hline DMSO & 11 & 3 & 3 & 3 & 20 \\
\hline ML351 & 12 & 3 & 2 & 1 & 18 \\
\hline WT & 9 & 3 & 0 & 0 & 12 \\
\hline LOX-KO & 7 & 4 & 0 & 0 & 11 \\
\hline
\end{tabular}

\section{Experimental sequence}

All animals were subjected to standard filament MCAO. After $2 \mathrm{hrs}$ of occlusion, the filament was withdrawn to initiate reperfusion and tPA (dissolved to $4 \mathrm{mg} / \mathrm{ml}$, final concentration of $10 \mathrm{mg} / \mathrm{kg} \mathrm{BW}$ ) was infused intravenously into the right jugular vein over 15 minutes using a perfusion pump. In the second part of the study, the 12/15-LOX inhibitor ML351 $(50 \mathrm{mg} / \mathrm{kg})$ or its vehicle DMSO $(60 \mu \mathrm{l})$ was given intraperitoneally before the tPA infusion was started. $0.1 \mathrm{mg} / \mathrm{kg}$ bodyweight buprenorphine hydrochloride 
(Buprenex®, Reckitt Benckiser Healthcare Ltd, Hull, HU8 7DS, UK) were administered at the end of all procedures.

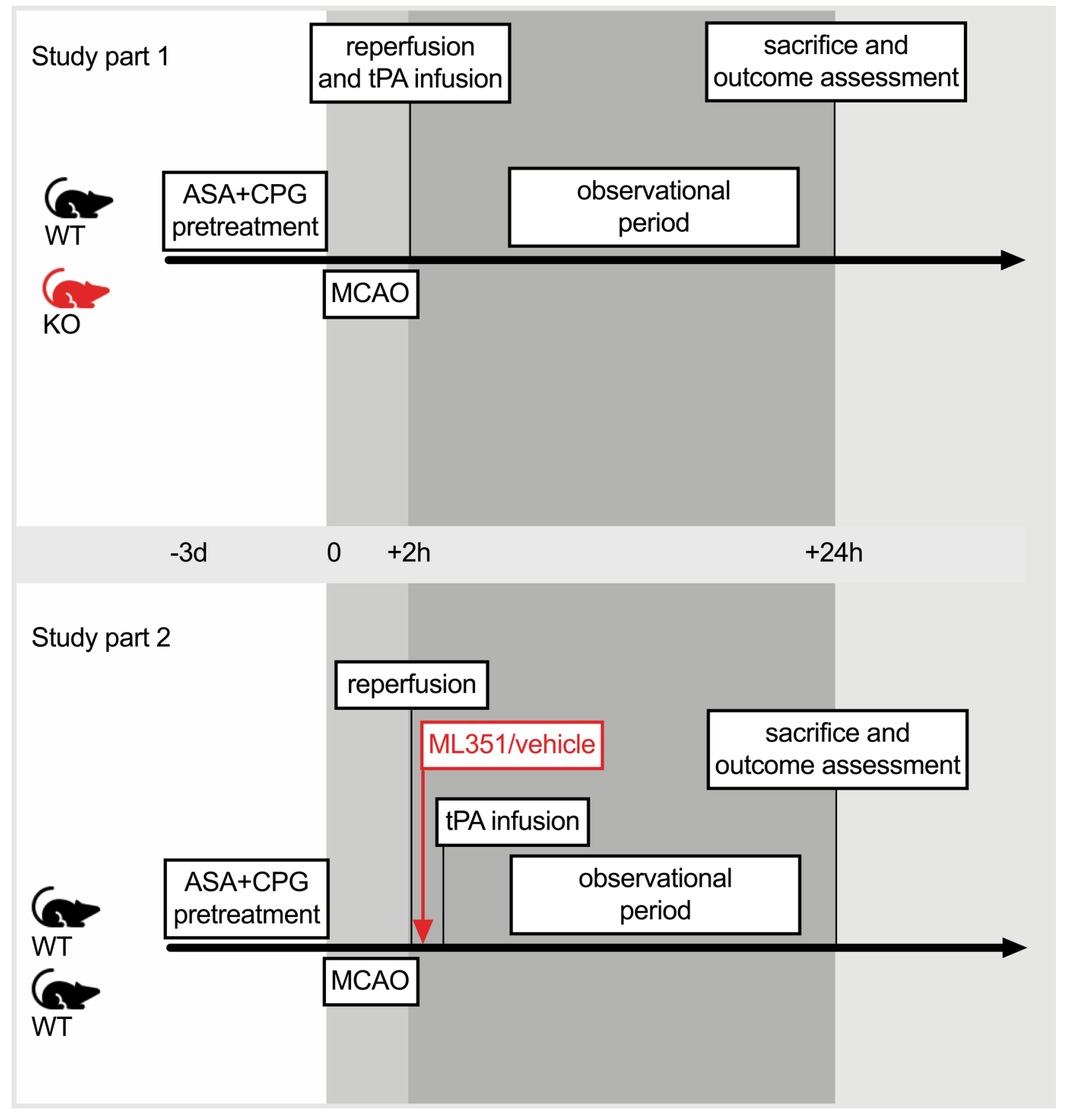

Figure: Study Design WT=wild type, $\mathrm{KO}=$ Knock out, $\mathrm{ASA}+\mathrm{CPG}=$ Aspirin + Clopidogrel, $\mathrm{MCAO}=$ middle cerebral artery occlusion, tPA=tissue plasminogen activator, $\mathrm{d}=$ days, $\mathrm{h}=\mathrm{hours}$ 


\section{HT determination}

24h after MCAO onset mice were lethally anaesthetized and perfused transcardially with saline. The brains were removed and cut into sections of $1 \mathrm{~mm}$ thickness (using a matrix) and photographed. The hemorrhages in the brain sections were rated on a 5point ordinal scale according to their morphological features ( $1=$ non hemorrhage; $2=$ small petechiae along the boundary of the infarct "hemorrhagic infarction type 1 (HI1)"; $3=$ confluent petechiae within the infarct "hemorrhagic infarction type 2 (HI-2)"; 4=blood clots within the infarct "parenchymal hemorrhage type1 $(\mathrm{PH}-1)$ "; $5=$ clots in $>30 \%$ of the infarct "parenchymal hemorrhage type2 ( $\mathrm{PH}-2)$ ") and an overall grade for every brain was determined according to the highest score occurring among the sections. An overall score of 3 or higher (presence of clot formation) was defined as significant ICH.

\section{Immunofluorescent Analysis of mice specimens}

$\mathrm{ASA}+\mathrm{CPG}$ mice were subjected to $2 \mathrm{~h} \mathrm{MCAO}$ and tPA treatment as indicated. After 24 hours, anesthetized mice were perfused transcardially with PBS followed by $4 \%$ paraformaldehyde. The brains were removed and fixed overnight, cryoprotected in $15 \%$ and $30 \%$ sucrose at $4{ }^{\circ} \mathrm{C}$. Frozen coronal sections $(20 \mu \mathrm{m})$ were prepared using a cryostat. After blocking with PBS containing $0.2 \%$ Triton X-100 and 3\% horse serum albumin for 1-2 hours, sections were incubated at $4^{\circ} \mathrm{C}$ overnight in a PBS $+0.2 \%$ Triton $X-100+2 \%$ horse serum albumin solution with rabbit polyclonal antibody against $12 / 15-$ LOX (1:100). Then the sections were washed and incubated with color labeled secondary anti-rabbit antibodies (1:200 in PBS containing 2\% horse serum albumin and $0.2 \%$ Triton $\mathrm{X}-100$ ) for $1 \mathrm{~h}$ at room temperature in the dark. The sections were washed again and incubated with DAPI, air dried, coverslip-mounted with 1 drop of mounting medium, sealed and stored at $-20^{\circ} \mathrm{C}$ until microscopy (Using a Nikon Eclipse fluorescent microscope with NIS Elements software for initial evaluation and a Zeiss LSM510 laser scanning confocal microscope at Ragon Institute of MGH, MIT and Harvard, 400 Technology Square, Cambridge, MA 02139-3583). 


\section{Schriftliche Erklärung}

Ich erkläre ehrenwörtlich, dass ich die dem Fachbereich Medizin der Johann Wolfgang Goethe-Universität Frankfurt am Main zur Promotionsprüfung eingereichte Dissertation mit dem Titel

„Stabilisierung der Blut-Hirn-Schranke nach Thrombolyse unter antithrombotischer Therapie durch LOX Inhibition“

in der Klinik für Neurologie (im Zentrum der Neurologie und Neurochirurgie) unter Betreuung und Anleitung von Prof. Dr. med. Christian Förch mit Unterstützung durch Dr. Klaus van Leyen ohne sonstige Hilfe selbst durchgeführt und bei der Abfassung der Arbeit keine anderen als die in der Dissertation angeführten Hilfsmittel benutzt habe.

Darüber hinaus versichere ich, nicht die Hilfe einer kommerziellen Promotionsvermittlung in Anspruch genommen zu haben.

Ich habe bisher an keiner in- oder ausländischen Universität ein Gesuch um Zulassung zur Promotion eingereicht noch die vorliegende Arbeit als Dissertation vorgelegt.

Vorliegende Ergebnisse der Arbeit wurden (oder werden) in folgendem Publikationsorgan veröffentlicht:

- Lieschke F, Zheng Y, Schaefer JH, van Leyen K, Foerch C; Measurement of Platelet Function in an Experimental Stroke Model With Aspirin and Clopidogrel Treatment; Frontiers in Neurology; 11(85); 2020

- Zheng $Y^{*}$, Lieschke $F^{*}$, Schaefer JH, Wang X, Foerch C, van Leyen K; Dual antiplatelet therapy increases hemorrhagic transformation following thrombolytic treatment in experimental stroke; Stroke; 50; 3650-3653; 2019; ${ }^{*}$ first shared

- Lieschke F, Zheng Yi, Foerch C, van Leyen K; Thrombolysis in acute stroke under dual antiplatelet therapy: Perspectives arising from translational studies; Neural

Regeneration Research; 16(1):113-114; 2020

- Lieschke F, Zheng Yi, Schaefer JH, Wang X, Lo EH, Foerch C, van Leyen K; Impaired Platelet Function after Combination Treatment with Aspirin and Clopidogrel contributes to 
tPA associated Hemorrhagic Transformation following Experimental Stroke; Poster Abstract International Stroke Conference der American Heart Association, 6.-8. Februar 2019, Honolulu, Hawaii

- Zheng Yi, Lieschke F, Foerch C, Wang X, van Leyen K; A Novel Mechanism for Hemorrhagic Transformation of Ischemic Strokes; Poster Abstract International Stroke Conference der American Heart Association, 6.-8. Februar, 2019, Honolulu, Hawaii

- Lieschke F, Zheng Yi, Schaefer JH, van Leyen K; Foerch C; Measurement of platelet function in a mouse model of tPA-associated hemorrhagic transformation in ischemic stroke following dual antiplatelet treatment; Poster Abstract European Stroke Organisation and World Stroke Organization Joint Stroke Conference, 12.-15. Mai, Wien, Österreich (verschoben auf den 6.-9.November 2020)

Frankfurt, (Ort, Datum) (Unterschrift) 


\section{Danksagung}

Abschließend möchte ich mich herzlich bei denen bedanken, die mich in meinem Studium und vor allem bei der Erstellung dieser Arbeit begleitet haben. Meine Dankbarkeit drücke ich insbesondere meinem Doktorvater, Prof. Christian Förch aus, der mich inspiriert und motiviert und ohne den diese Arbeit nicht entstanden wäre. Genauso danke ich Dr. Klaus van Leyen, der mich Teil seiner Arbeitsgruppe hat werden lassen und der mir mit viel Geduld das wissenschaftliche Arbeiten lehrt. Des Weiteren danke ich Dr. Jan Hendrik Schäfer, der mich in dieses Projekt einführte und mich mit vielen Ratschlägen während der experimentellen Phase unterstützte. Zuletzt möchte ich noch meine Familie und Freunde nennen und euch von ganzem Herzen für eure unendliche Unterstützung danken, dafür dass ihr immer für mich da seid und mir den Rücken frei haltet.

\section{Eure Franziska}

